\title{
Monopoly Versioning of Information Goods When Consumers Have Group Tastes
}

\author{
Xueqi (David) Wei ${ }^{\dagger}$ \\ and \\ Barrie R. Nault ${ }^{\dagger \dagger}$ \\ ${ }^{\dagger}$ School of Management \\ Fudan University \\ weixueqi@fudan.edu.cn \\ ${ }^{\dagger \dagger}$ Haskayne School of Business \\ University of Calgary \\ nault@ucalgary.ca
}

September 2, 2013

Copyright (c)2013 by Xueqi (David) Wei and Barrie R. Nault. All rights reserved. 


\title{
Monopoly Versioning of Information Goods When Consumers Have Group Tastes
}

\begin{abstract}
Large sunk costs of development, negligible costs of reproduction and distribution resulting in economies of scale distinguish information goods from physical goods. Versioning is a way firms may take advantage of these properties. However, in a baseline model where consumers differ in their tastes for quality, an information goods monopolist only offers one version, and this differs from what we observe in practice. We explore formulations that add features to the baseline model that result in a monopolist offering multiple versions. We examine versioning where consumers differ in individual tastes for quality, and groups of consumers that share the same group taste are delineated by segments of individual tastes. We find that if groups have mutually exclusive characteristics - a horizontal dimension - that they value relative to the shared characteristics, then versioning is optimal. Consequently, any horizontal differentiation in product line design favors versioning. In addition, when group tastes are hierarchical such that higher taste groups value characteristics that lower taste groups value but not vice versa - a vertical dimension, as long as the valuations of the higher and adjacent lower taste group are sufficiently close, then versioning is also optimal. Our conditions, which also help determine how many versions are optimal, are based on exogenously defined parameters so that it is feasible to check them in practice.
\end{abstract}

Keywords: Information Goods, Market Segmentation, Product Differentiation, Versioning Strategies, Pricing Strategies.

Received May 2010; accepted August 2013 by Cheryl Gaimon after four revisions. 


\section{Introduction}

Information goods such as computer software, online services, online content and digitalized music, movies and books are an indispensable part of our life. A critical distinction between information and physical goods is that the former incurs large sunk costs of development but negligible costs of reproduction and distribution. Broad adoption of e-commerce, secure and convenient online payments and high-speed Internet have greatly lowered transaction costs and expanded markets for information goods. In addition to production costs, due to developments in software engineering the functionality of information goods such as computer software can be easily restricted or recombined to generate different versions, the popularity of modularity in software design brings flexibility in delivery of various versions, and information goods are durable goods that a consumer typically purchases once.

Price discrimination and product differentiation are strategies firms can use to take advantage of information goods. A common practice is to offer a menu of goods and prices, and each consumer chooses based on their preference: second degree price discrimination. In this context Bakos and Brynjolfsson (1999) found that bundling many unrelated information goods can be profitable, but Geng et al. (2005) found when groups of consumers differ systematically in their valuations, simple bundling is not optimal. Nonlinear pricing can also increase monopoly profits, and can be used to avoid direct competition. Sundararajan (2004) showed that for some information goods, fixed-fee and usage-based pricing together can maximize a monopolist's profit. In duopoly, Choudhary (2010) showed that pricing schemes such as per user pricing and site licensing allows competing sellers to differentiate.

An alternative to bundling and non-linear pricing is versioning. Versioning through vertical differentiation has been modeled with network externalities (Jing 2007, Cheng and Tang 2010), competition (Jones and Mendelson 2011, Wei and Nault 2006), anti-piracy (Wu and Chen 2008, Chellappa and Shivendu 2005), and interorganizational systems (Nault 1997). They all conclude that versioning is not optimal without certain constraints, consistent with Bhargava and Choudhary (2001). Indeed, a surprising and critical result is when consumers differ in tastes for quality, an information goods monopolist offers only one version. This 
is in contrast to numerous observations in practice that information goods monopolies or near-monopolies use versioning. This has given rise to an emergent research program that provides alternative explanations through alternative analytical model formulations. Thus, the research program in versioning information goods is directed towards showing conditions under which a monopolist offers multiple versions.

In addition to enhancing the problem setting with externalities, competition, anti-piracy, and interorganizational systems, prior work has also refined utility function specifications. With a marginal utility function linearly decreasing in quality, Varian (1998) first explored conditions when versioning is optimal. Adopting quadratic utility, Ghose and Sundararajan (2005) proposed optimal solutions with multiple versions. Chen and Seshadri (2007) introduced convex reservation utilities when consumers have outside options to explain multiple versions. Bhargava and Choudhary (2008) showed that versioning is optimal when lower type consumers have greater ratios of valuations than higher type consumers. Lacourbe et al. (2009) showed that when consumers are heterogeneous in their tastes for different features (a horizontal dimension) and in their tastes for quality (a vertical dimension), and when development costs dominate and variable costs are zero, the monopolist's optimal product portfolio is based solely on horizontal differentiation.

Although these modeling results are consistent with many empirical observations, there are other observations of practice that are not effectively explained. Well-known are the different editions in the individual generations of Microsoft's Operating Systems. Windows XP, first released in 2001, has five editions, and Windows Vista, fully released in 2007, has four editions. Within each generation some editions are vertically differentiated and others are horizontally differentiated. In another product segment, Matlab delivers a standard software module together with separate add-on modules so that consumers can select add-on modules to generate customized versions that are either horizontally or vertically differentiated (http://www.mathworks.com/ products/matlab/?sec=extending).

To make our analysis concrete we use two examples - one horizontal and one vertical. A classic horizontal differentiation example is Kurzweil's product line of software-based voice recognition products (Shapiro and Varian 1999). Kurzweil offers seven versions and among 
them Office Talk is designed for office staff, Law Talk for lawyers, Voice Med for medical staff, and Voice Ortho for surgeons. Each version is priced differently based on different vocabulary sets, and all of the versions share a certain amount of common vocabulary (about 20,000 words). The high-end version for surgeons is priced a hundred times higher than the entry-level VoicePad Pro version.

Our vertical differentiation example is Windows 7, released in 2009. Although there are six different editions, only Home Premium, Professional, and Ultimate are widely available. Within the six editions, there is increasing functionality for each edition, indicating vertical differentiation (see comparison table in http://en.wikipedia.org/wiki/Windows_7_editions). Moreover, Home Basic is only offered in emerging markets. It is not available in first world countries. Thus, in emerging markets there may be a separate group of novice home users so that providing an extra version for that market may be profit maximizing. These and other versioning examples are given in Table 1.

\begin{tabular}{|c|c|c|}
\hline $\begin{array}{l}\text { Industry } \\
\text { Examples }\end{array}$ & Versions Offered & Targeted Consumers \\
\hline \multirow{6}{*}{ Windows 7} & Starter & Entry level consumers, pre-installed by OEMs \\
\hline & Home Basic & Entry level consumers in emerging market \\
\hline & Home Premium & A majority of proficient individual users \\
\hline & Professional & Users associated with small business \\
\hline & Enterprise & $\begin{array}{l}\text { Advanced business users in managed } \\
\text { environment }\end{array}$ \\
\hline & Ultimate & PC Enthusiasts \\
\hline \multirow{7}{*}{$\begin{array}{l}\text { Kurzweil } \\
\text { Voice } \\
\text { Recognition } \\
\text { Software }\end{array}$} & VoicePad Pro & Entry level consumers \\
\hline & Personal & A majority of individual consumers \\
\hline & Professional & Proficient consumers \\
\hline & Office Talk & General office staff \\
\hline & Law Talk & Legal officials \\
\hline & Voice Med & Medical officials \\
\hline & Voice Ortho & Special purpose medical officials \\
\hline \multirow{4}{*}{ Stata } & Stata/MP & Multicore/multiprocessor computers \\
\hline & Stata/SE & Large datasets \\
\hline & Stata/IC & Moderate-sized datasets \\
\hline & Small Stata & Small datasets \\
\hline \multirow{4}{*}{$\begin{array}{l}\text { Adobe } \\
\text { Creative } \\
\text { Suite } 5\end{array}$} & Design Premium & General purpose designers \\
\hline & Web Premium & Web designers \\
\hline & $\begin{array}{l}\text { Production } \\
\text { Premium }\end{array}$ & Video editors and motion graphic designers \\
\hline & Master Collection & Full range creative tools for enthusiastic users \\
\hline \multirow{3}{*}{$\begin{array}{l}\text { Oracle } \\
\text { Database } \\
11 \mathrm{~g}\end{array}$} & $\begin{array}{l}\text { Oracle Database } \\
\text { Enterprise Edition }\end{array}$ & $\begin{array}{l}\text { Single and clustered servers with no socket } \\
\text { limitation }\end{array}$ \\
\hline & $\begin{array}{l}\text { Oracle Database } \\
\text { Standard Edition }\end{array}$ & Servers with up to four sockets \\
\hline & $\begin{array}{l}\text { Oracle Database } \\
\text { Standard Edition } \\
\text { One }\end{array}$ & $\begin{array}{l}\text { Single servers with maximum capacity of two } \\
\text { sockets }\end{array}$ \\
\hline
\end{tabular}

Table 1: Industry Examples of Versioning 
Whether in product line design or versioning, some articles treat consumers as a continuum of types (Jing 2007, Bhargava and Choudhary 2001, 2008) while others treat consumers as a set of discrete types (Jones and Mendelson 2011, Moorthy 1984). The major contribution of our work is that we introduce a group taste to link both: individual tastes are continuous while group tastes are discrete. With this structure, we can not only explain when versioning is optimal, but also provide information goods vendors with powerful tools to analyze versioning strategies and determine how many versions to offer. We use group taste to explain two dimensions of versioning - horizontal and vertical - and derive conditions to determine when versioning is optimal. The key managerial insight is that versioning must be based on existing market segments - natural segments defined by group tastes.

Essential to our model is the definition of an individual consumer taste for quality, and a group taste that is correlated with the individual taste. That is, separate groups of consumers that share the same group taste are delineated by segments of these individual tastes. We show that if there is only one group, then the classic result whereby a monopolist offers only a single version - found by others, holds. We then define two separate utility specifications and show how each supports versioning. To begin, we specify a preference structure such that some of the information good's characteristics are valuable to all groups and other characteristics are only valuable to one group - we name former shared characteristics and the latter mutually exclusive characteristics where these characteristics horizontally differentiate the groups. We find that when different groups place sufficient value on the mutually exclusive characteristics relative to the shared characteristics, versioning is optimal. Moreover, as the utility gained from the shared characteristics increases with quality, our results tend toward the single version solution, i.e., the amount of the lowest-priced group decreases. Nonetheless, any differentiation in product line design favors versioning.

Next, we specify a preference structure with hierarchical characteristics where higher taste groups value characteristics that lower taste groups value, but not vice versa. This structure effectively defines vertical differentiation by increasingly broadening the characteristics to which the individual and group taste applies. We derive sufficient and necessary conditions based on group tastes and the distribution of individual tastes that determine 
when versioning using vertically differentiated goods is optimal - effectively this condition holds when the overall valuation of the higher taste group is close to that of the next lowest taste group. Furthermore, we provide conditions for the monopolist to determine which groups should be served with separate customized versions - essentially determining how many versions should be offered.

The rest of the paper is as follows. We set up our notation and assumptions in Section 2. We investigate horizontal versioning when groups have mutually exclusive characteristics in Section 3. We examine vertical versioning when groups have hierarchical characteristics in Section 4. In Section 5 we discuss our contributions, future research and limitations.

\section{Model Notation and Assumptions}

Following the hedonic hypothesis that "goods are valued for their utility-bearing attributes or characteristics" (Rosen 1974, pp. 34), we define information goods as a combination of characteristics, and quality is defined as an aggregation of values that consumers get from these characteristics. Thus, quality is determined by the set of characteristics, and more characteristics yield higher quality. It may be helpful to think of characteristics as functionality or as content. We denote quality as $q \in R^{+}$. We presume that complexity of information goods does not jeopardize their quality levels and that unused characteristics can be freely disposed of or ignored in use. We abstract from increasing complexity from additional characteristics negatively affecting quality - an issue rendered less important with improvements in information technology.

Following a broad literature on vertical differentiation, we take consumers to be heterogeneous and continuously distributed in their individual taste for quality. We denote the individual consumer taste for quality as $\theta \in\left[\theta_{0}, \theta_{h}\right]$. Over the population of consumers $\theta$ has density and cumulative density functions $f(\theta)$ and $F(\theta)$, respectively, so that consumers are normalized with a unit population. The density is positive over its support and continuously differentiable. Following Bhargava and Choudhary (2001), Jing (2007) and Sundararajan (2004), we make the now-standard assumption about the distribution of consumer taste: 
Assumption 1 The reciprocal of the hazard function, $\frac{1-F(\theta)}{f(\theta)}$, is non-increasing in $\theta$.

Assumption 1 assures unique solution for $\theta=\frac{1-F(\theta)}{f(\theta)}$ by ensuring that if a lower taste consumer obtains positive utility from purchasing, then a higher taste consumer will as well. This assumption is satisfied by common distributions such as the uniform, normal, logistic, chi-squared, exponential, Laplace, and any distribution with increasing density (Bhargava and Choudhary 2001).

Consumers also belong to groups. When a consumer belongs to a particular group, that consumer together with all other consumers in the group have similar preferences for certain characteristics. For example, if we define two groups such as students and professors, then although students are individually different they share preferences for certain characteristics and thus show similar valuations as other students. Apart from professions, other indicators such as demographics and geographic location are also commonly used to define groups. This is traditionally how firms define market segments (Frank et al. 1972). When a monopolist develops goods targeted to certain groups, it accentuates characteristics for which members of the group have similar preferences. This explains why Microsoft develops functions for Windows Vista such as "Easily make DVDs" and "Create high-definition movies" for the Home Premium Edition, and includes functions such as "Remote desktop connection" and "Windows fax and scan" for the Business Edition.

To capture preferences that are common to all individuals within a group, we define a second dimension that determines an individual's taste for quality: a group taste. We divide consumers into $h$ separate groups and directly relate these groups to individual tastes by defining each group as a segment of the distribution of individual tastes. Effectively this means that individual taste and group taste are positively related so that consumers with higher group taste are associated with higher individual taste.

Definition 1 (Group Tastes) Consumers with individual taste in segment $\left[\theta_{n-1}, \theta_{n}\right)$ belong to group $n, n \in\{1, \cdots, h\}$. Consumers in the same group $n$ share the same group taste $k_{n} \in R^{+}$and groups from higher individual taste segments have greater group tastes for quality, which means $k_{n+1} \geq k_{n}$. 
Our definition of group tastes is based on, and limited by, the relationship between individual and group taste. Hence, our definition implies a strong ordering between individual and group tastes, and does not admit a consumer with lower individual taste than another consumer also having higher group taste. To implement our combination of individual and group tastes, we represent the taste for quality as a product of the individual and group taste. This implies little loss of generality as we can simply rescale $q$ ( or $\theta$ ), and is our next assumption:

Assumption 2 (Multiplicative Utility) The utility function of consumers $\theta \in\left[\theta_{n-1}, \theta_{n}\right.$ ) (belonging to group $n$ ) who purchase information good with quality $q$ is $U\left(q, \theta, k_{n}\right)=k_{n} \theta q$.

Figure 1 illustrates how the utility function becomes piecewise linear over the range of individual tastes due to the steps in group taste. As can be seen from the figure, the strongordered setting amplifies individual taste differences, and this strong-ordering of preferences provides the necessary structure for our versioning results.

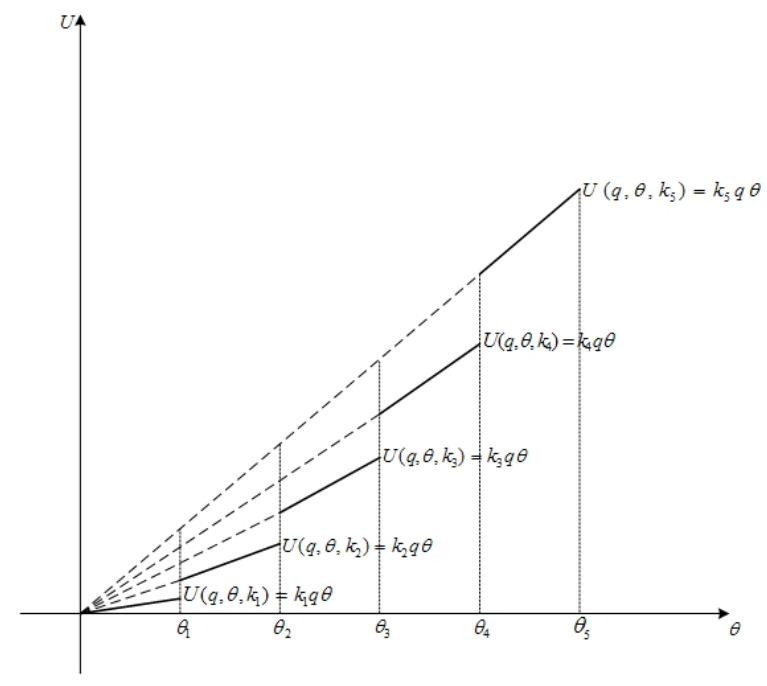

\section{Figure 1: Utility Functions of Consumers in Different Segments}

For analytical convenience, we scale the utility function $U\left(q, \theta, k_{n}\right)$ in value terms so that it can be directly compared with prices. This combination of individual and group tastes allows us to represent discontinuous consumer heterogeneity, and proposes a hierarchical structure of consumers that is frequently observed in practice. For example, consumers in 
Asian countries such as China and India systematically have lower willingness to pay for information goods than consumers in North American countries such as US and Canada. Even within the same geographic area, students are systematically willing to pay less for certain information goods than professors. In both cases, group features amplify individual differences. Varian (2000) also divides consumers into groups (clubs) by their willingness to pay when investigating optimal solutions for buying, sharing and renting information goods. Our assumption is restrictive in the sense that the group taste measure is linearly homogeneous - that is, it is multiplicatively separable from individual taste. Moreover, it is correlated with individual taste in that group taste is weakly increasing in segments of individual consumer taste.

Our additional group taste dimension follows a substantial literature where groups of consumers have the same taste or consumers are modeled as having multiple dimensions of taste. Moorthy (1984) treated different groups of consumers as discrete points so that each consumer in a particular group has the same taste, and Jones and Mendelson (2011) modeled individual consumer taste with a uniform distribution, implicitly assuming there is only one group in the market. Indeed, all models that have high and low types of consumers effectively define homogeneous consumer groups. Vandenbosch and Weinberg (1995) used two continuous consumer taste dimensions in an additive utility function where each taste is multiplied by a characteristic of the good. Caplin and Nalebuff (1986) used $n$ dimensions of consumer tastes matched to $n$ characteristics in a Cobb-Douglas utility function with each characteristic raised to its taste parameter - taking the log yields the form used by Vandenbosch and Weinberg (1995). Canoy and Peitz (1997) had a taste parameter for quality and another taste in a horizontal dimension, and similarly Lacourbe et al. (2009) had a taste parameter for quality and a horizontal dimension for features. Even closer to our specification, Corstjens and Lal (2000) defined taste based on consumer income and used a bimodal distribution over a parameter representing brand inertia, effectively defining groups based on brand inertia. Finally, Bonatti (2008) used a brand-specific premium proportional to quality that depends on consumer taste and preference for a particular brand. Empirically, Sultan and Chan (2000) studied how individual adoption of software was affected by characteristics of the individual, group and firm, showing that group characteristics play a definitive role in 
individual valuation.

We extend our basic utility structure that includes group tastes for multiple groups in two separate specifications. To begin, we define a utility structure where all consumers can derive value from a shared set of information good characteristics, while other characteristics provide value for specific groups. Based on product line engineering, different versions within a product line normally share a common, managed set of characteristics (Birk et al. 2003), while others can be designed for specific consumer groups. Thus, the value that consumers can derive from specific sets of additional characteristics is mutually exclusive between groups. This is similar to horizontal differentiation by features in Lacourbe et al. (2009). Here we take $q_{a} \in R^{+}$to be the quality of the shared characteristics alone, and for a consumer belonging to group $n$ we take $q_{n} \in R^{+}$to be the quality of the information good with specific characteristics for group $n$, and consequently $q_{n} \geq q_{a}$.

Assumption 3 (Utility with Mutually Exclusive Characteristics) If a consumer $\theta \in$ $\left[\theta_{n-1}, \theta_{n}\right)$ (belonging to group $n$ ) purchases the information good customized for group $n$, then their utility is $U\left(q_{n}, \theta, k_{n}\right)=k_{n} \theta q_{n}$. If a consumer $\theta \in\left[\theta_{i-1}, \theta_{i}\right)$ where $i \neq n$ (not belonging to group $n$ ) purchases the information good customized for group $n$, then their utility is $U\left(q_{n}, \theta, k_{i}\right)=k_{i} \theta q_{a}$.

The critical feature of Assumption 3 is that the additional characteristics that each group values are mutually exclusive. If a consumer from group $n$ purchases the information good customized for group $n$, then the consumer receives the full utility embedded in the characteristics of the good. Otherwise, if a consumer purchases the "wrong" good (one customized for another group), then the consumer only gets utility from the shared characteristics, those in $q_{a}$. Therefore, utility is not increasing in $\theta$ except for consumers in group $h$. An example that fits utility with mutually exclusive characteristics is Kurzweil's voice recognition software. The shared characteristics are the interface and the common vocabulary. The group-specific characteristics are profession-related such as specific vocabulary for lawyers and physicians whereby lawyers do not value the medical vocabulary and vice-versa for physicians and legal vocabulary. 
Next, we consider a utility structure in which information goods characteristics designed for each group are hierarchical. We start with the shared set of characteristics, which yields quality $q_{a}$, which we can rename as $q_{1}$ for reasons that will be evident shortly. All consumers receive value from $q_{1}$. The hierarchical structure of characteristics is defined through our quality measure, $q$. If a set of additional characteristics is related to group $n$, then not only consumers in group $n$ value the characteristics embedded in $q_{n}$, all the higher taste groups value this set of characteristics and all lower taste groups do not. Thus, here $q_{n}$ represents a quality aggregation of the information good characteristics valued by groups $\geq n$.

Assumption 4 (Utility with Hierarchical Characteristics) If a consumer $\theta \in\left[\theta_{n-1}, \theta_{n}\right.$ ) (belonging to group $n$ ) purchases the information good customized for group $n$, then their utility is $U\left(q_{n}, \theta, k_{n}\right)=k_{n} \theta q_{n}$. If a consumer with $\theta<\theta_{n-1}$ belonging to a lower taste group $i<n$ purchases the information good customized for group $n$, then their utility is $U\left(q_{n}, \theta, k_{i}\right)=k_{i} \theta q_{i}$. If a consumer with $\theta \geq \theta_{n-1}$ belonging to a higher taste group $j>n$ purchases the information good customized for group $n$, then their utility is $U\left(q_{n}, \theta, k_{j}\right)=k_{j} \theta q_{n}$.

The key feature in utility with hierarchical characteristics is that consumers in lower taste groups do not value characteristics designed for higher taste groups, thus defining vertical differentiation by increasingly broadening the characteristics to which the individual and group taste applies. Using our example of Windows 7, characteristics designed for the Home Premium edition are valued by home and power users, and special characteristics such as server functions designed for Professional edition are only valued by power users. Moreover, server functions and other functionality in the Professional edition are valued by power and enterprise users, but multi-display support and distributed cache together with other industrial-level functions available in the Ultimate edition are only valued by enterprise users.

Our utility with mutually exclusive characteristics (Assumption 3) and utility with hierarchical characteristics (Assumption 4) are related through the group taste and the characteristics, as measured through the different qualities $q_{i}$, to which individual and group tastes apply. If a consumer purchases the good customized for their group, then they receive the same value in both utility specifications: $k_{n} \theta q_{n}$. If a consumer purchases a good that is not 
customized for their group, then they only receive the utility associated with their group from the characteristics from which the group can derive value: for utility with mutually exclusive characteristics it is the shared characteristics $q_{a}$, and for utility with hierarchical characteristics it is minimum of the characteristics designed for their group and lower groups or the characteristics of the purchased good.

Providing separate version for different groups of consumers may incur additional costs which we refer to as "versioning costs". Versioning costs could include additional development, marketing and managerial costs. Technology development such as software engineering has greatly lowered additional development costs for versioning and broad adoption of e-commerce has minimized additional marketing and managerial costs for providing an extra version. Moreover, if all features are developed on a common platform and activating or disabling sets of features incurs virtually no costs, then versioning costs are further minimized. Thus, we make the following limiting assumption about versioning costs:

Assumption 5 Versioning costs are zero after the highest quality information goods have been produced.

In practice, software developers usually develop a flagship version with the full set of features, where the features can be different combinations of functionality and content. Then developers can progressively disable features to generate versions. The result is either a sequence of increasingly less capable versions, or a base version with additional optional components. This is common in statistical software where Stata offers a set of increasingly restricted versions, and where SAS offers a base version to which modules can be added.

The Monopolist's Profit Maximization Problem Across our two utility structures defined in Assumptions 3 and 4, we can state generic individual-rationality (IR) and incentivecompatibility (IC) conditions that apply to consumers deciding which version to purchase. In our model, the IC and IR conditions are constructed so that consumers only consider purchasing the good customized for their group. In other words, our IR and IC conditions effectively prevent consumers in one group from purchasing good designed for another 
group: cross-purchasing. In practice, the monopolist would likely avoid the cross-purchasing problem during the software design process (Ullah et al. 2010).

In segment $n$ where consumers only choose between purchasing the good customized for their group and not purchasing, we define the IR condition so that consumers receive non-negative value from purchasing:

$$
U\left(q_{n}, \theta, k_{n}\right)-p_{n} \geq 0, \theta \in\left[\theta_{n-1}, \theta_{n}\right) . \quad[\mathrm{IR}]
$$

In segment $n$ where consumers choose between purchasing the good customized for their group $n$ and a good customized for another group $i$, we define the IC condition so that consumers weakly prefer to purchase the good customized for their group:

$$
U\left(q_{n}, \theta, k_{n}\right)-p_{n} \geq U\left(q_{i}, \theta, k_{n}\right)-p_{i}, \theta \in\left[\theta_{n-1}, \theta_{n}\right) \forall i . \quad[\mathrm{IC}]
$$

For the indifferent consumer, $\tilde{\theta}_{n}$, either the IR condition in (1) is binding, the IC condition in (2) is binding, or both.

The profit maximization for a monopolist that serves up to $h$ groups is

$$
\begin{aligned}
\max _{\tilde{\theta}_{1}, \cdots, \tilde{\theta}_{h}} \Pi\left(\tilde{\theta}_{1}, \cdots, \tilde{\theta}_{h}\right)=\max _{\tilde{\theta}_{1}, \cdots, \tilde{\theta}_{h}}\left\{\sum_{n=1}^{h} p_{n}\left(\tilde{\theta}_{1}, \cdots, \tilde{\theta}_{h}\right)\left[F\left(\theta_{n}\right)-F\left(\tilde{\theta}_{n}\right)\right]\right\} \\
\text { s.t. [IR], [IC] }], \tilde{\theta}_{n} \in\left[\theta_{n-1}, \theta_{n}\right) .
\end{aligned}
$$

In (3), if the optimal indifferent consumer $\tilde{\theta}_{n}=\theta_{n-1}$, then it means group $n$ is fully covered. On the other hand, if the optimal indifferent consumer is obtained at its upper limit $\theta_{n}$, then it means group $n$ is not served with a separate version at all. We know at the optimum the [IR] and [IC] conditions in (1) and (2) hold for all groups served in (3), and prices in (3) come from the IR and IC conditions.

In our model of utility with mutually exclusive characteristics, the single-crossing condition whereby the marginal utility of taste is increasing in quality does not hold as consumers that purchase a good not designed for their group only receive the quality of the shared characteristics. Consequently, for this model the revelation principle does not hold, which means restricting cross-purchasing may be sub-optimal. We begin our model by restricting cross-purchasing with the IC condition, and relax the IC condition to explore when cross-purchasing is allowed. 
In our model of utility with hierarchical characteristics, due to the revelation principle the monopolist can restrict attention to prices such that consumers truthfully reveal their types, meaning that profits for the monopolist can be optimized by setting prices such that consumers choose the information good that is customized for their group (see Fudenberg and Tirole 1991; details are also included in the proof of Lemma 1). The revelation principle causes the monopolist's optimal prices to preserve the strong-ordering of consumer groups to the good customized for their group.

\section{Mutually Exclusive Characteristics and Horizontal Differentiation}

We examine versioning when a monopolist faces different groups of consumers that have utility with mutually exclusive characteristics as per Assumption 3 such as voice recognition software (Kurzweil) with medical vocabulary for physicians and legal vocabulary for lawyers. We begin by examining when there is no cross-purchasing, and then later relax the IC constraint to allow for cross-purchasing.

\subsection{No Cross-Purchasing}

Taking the different versions $q_{1}, \ldots, q_{h}$ across the $h$ groups, the profit maximization where prices of each version are determined by the optimal solution to (3). For consumers in groups $n$ that are served (i.e., purchase a version), $n \in\{1,2, \cdots, h\}$, the optimal prices must satisfy the IR and IC conditions in (1) and (2). That is, prices are set so that consumers in the higher taste group prefer to purchase the good customized for their group rather than purchasing good customized for a lower taste group (i.e., cross-purchasing), and the monopolist may choose not to serve consumers in some lower taste groups.

If the IC condition is binding, then it is when the indifferent consumer in the highest taste group obtains the same value from purchasing the lowest priced version. The comparison with the lowest priced version is because if a consumer purchases a good customized for another group, then that consumer only obtains utility from the shared characteristics $q_{a}$, 
regardless which other group the purchase is from. Thus, if the IC condition binds, it is where $p_{n}$ is the minimum over $n \in\{1, \ldots, h-1\}$. The IC condition for this specific case is,

$$
U\left(q_{h}, \tilde{\theta}_{h}, k_{h}\right)-p_{h} \geq U\left(q_{a}, \tilde{\theta}_{h}, k_{h}\right)-p_{n}
$$

When the IR constraint is binding the left hand side is zero, and in this case the IR constraint is binding for group $n$ so that $p_{n}$ is set from the binding IR constraint $U\left(q_{n}, \tilde{\theta}_{n}, k_{n}\right)=p_{n}$. Substituting with our utility function form from Assumption 3, we have

$$
\frac{q_{a}}{q_{n}} \leq \frac{k_{n} \tilde{\theta}_{n}}{k_{h} \tilde{\theta}_{h}}, n \in\{1, \cdots, h-1\},
$$

Equation (5) is the special case of the more general condition $U\left(q_{a}, \tilde{\theta}_{h}, k_{h}\right) \leq U\left(q_{n}, \tilde{\theta}_{n}, k_{n}\right), n \in$ $\{1, \cdots, h-1\}$ whereby the utility an indifferent consumer from a lower taste group obtains from the good customized for their group is at least as great as the utility obtained by the indifferent consumer in the highest taste group from the shared characteristics from a good customized for other groups. Because consumers with high individual tastes also have high group tastes, consumers in group $h$ have the highest utility for shared characteristics, and are the most likely to purchase goods customized for other groups. We can now state our versioning theorem for utility with mutually exclusive characteristics. The proofs of this and subsequent results are in the on-line Appendix.

Theorem 1 (Versioning for Utility with Mutually Exclusive Characteristics) A sufficient condition for multiple versions is that there exists an $n \in\{1, \cdots, h-1\}$ so that $\frac{q_{a}}{q_{n}}<\frac{k_{n} \theta_{n}}{k_{h} \theta_{h}^{*}}$, where $\theta_{h}^{*}$ is the indifferent consumer in segment $h$ when it is optimized separately.

This result is derived directly from the condition in (5), but in terms of exogenous variables $q_{a}, q_{n}, k_{n}, k_{h}, \theta_{n}$ and the result of a straightforward optimization $\left(\theta_{h}^{*}\right)$ which provides useful guidelines to determine whether a separate version should be offered. The intuition behind Theorem 1 is that if there is at least one consumer in the lower taste group so that the highest taste group would not cross-purchase, then versioning is optimal.

Theorem 1 is robust to the group taste component of preferences being weakly strongordered, that is, $k_{1} \leq k_{2} \leq \ldots \leq k_{h}$. It is straightforward to show that if the highest group 
is covered $\left(\theta_{h}^{*}=\theta_{h-1}\right)$ and the values of the group taste component are equal across groups $\left(k_{1}=k_{2}=\ldots=k_{h}\right)$, as long as there are customized characteristics, then versioning is always optimal. Thus, even small horizontal differentiation in product line design via mutually exclusive characteristics favors versioning. Meanwhile, shared characteristics restrict versioning because they encourage cannibalization between versions. If we further assume that individual taste is equal across consumers, then the mutually exclusive characteristics actually determine the price difference for each version. That is because the price of a version is the sum of utility from the shared characteristics (which is the same) and the additional utility from the customized characteristics, and versioning is always preferred. In this setting, versioning becomes a multi-product bundling problem.

Critical to the condition in (5) is the proportion of quality that comes from shared characteristics - in our Kurzweil example the shared characteristics is the vocabulary that is common among versions. If the condition in (5) holds for all groups $(\forall n \in\{1, \ldots, h-1\})$, then the shared characteristics do not provide enough value for consumers in group $h$ to purchase goods customized for any of the other groups. In this situation, it is optimal for the monopolist to provide each group with a customized version. The rationale is simple. As compared to the value of group-specific characteristics, if the value of shared characteristics is relatively low, then each consumer chooses the right version for their group - that is, the good customized for it. When there are no shared characteristics, each group values only its own mutually exclusive characteristics, and we have a "perfect horizontally differentiated market" where a variant of third degree price discrimination applies (Frank et al. 1972).

If the condition in (5) is not satisfied for at least one group, then there exists a lower taste group where at least one consumer from the highest taste group can be better off purchasing the good customized for the lower taste group: cross-purchasing. In this case the result of the monopolist's profit maximization is that the IC condition is binding and a lesser number of consumers in the lower taste group purchase - indeed, this is why the condition in (5) is not necessary for versioning in Theorem 1 as versioning may still be optimal through the binding IC condition when the IR condition is not binding. If the value of the shared characteristics is sufficiently high, then the monopolist is better off not serving the lower taste group at 
all. Consequently, the monopolist offers fewer versions than the number of consumer groups. In the Kurzweil example this may be why versions are not offered for some professions like engineers and accountants, but are offered for lawyers and physicians. If the IC condition drives all groups with lower taste other than the highest taste group to be closed, then only one version is offered. This reasoning forms the basis of our comparative statics below.

Comparative Statics of Shared Characteristics From the perspective of information goods development, shared characteristics - especially through the development of a single platform - may ensure quality, improve efficiency and provide better manageability (Birk et al. 2003, Cottrell and Nault 2004). We examine what occurs as the quality from shared characteristics increases - typically when there are additional shared characteristics.

Beginning with the case where there are no shared characteristics, the condition in (5) is not binding, and consequently the optimization in (3) becomes a collection of separate optimization problems - one for each consumer group:

$$
\theta_{n}^{*} \text { s.t. }\left\{\theta: \frac{F\left(\theta_{n}\right)-F(\theta)}{f(\theta)}=\theta, \theta \in\left[\theta_{n-1}, \theta_{n}\right)\right\},
$$

for $\theta_{n}^{*}, n \in\{1,2, \cdots, h\}$. From Assumption 1, we get that the first derivative of $\frac{F\left(\theta_{n}\right)-F(\theta)}{f(\theta)}$ with respect to $\theta$ is also non-increasing for $\theta \in\left[\theta_{n-1}, \theta_{n}\right)$ (detailed proof is included in the on-line appendix), which means there is at most one interior solution for $\theta_{n}^{*}, \theta \in\left[\theta_{n-1}, \theta_{n}\right)$. If there is no interior solution, then the monopolist sets $\theta_{n}^{*}=\theta_{n-1}$ to maximize profits for group $n$, which means everyone in this group purchases. In this case of no shared characteristics, the condition in (5) holds with weak inequality for all $n \in\{1, \ldots, h-1\}$.

As the quality of the shared characteristics increases, at some point the condition in (5) binds for the lowest priced group. When (5) is binding for one or more groups, the monopolist no longer prices versions customized for different groups independently. To satisfy the IR and IC conditions, the monopolist has to adjust its pricing scheme to make sure consumers in each group choose the good that is customized for them. The following proposition describes the adjustment. 
Proposition 1 When there is threat of cross-purchasing for one or more groups, an increase in the quality of the shared characteristics (weakly) reduces the proportion of the lowest priced group that is served.

The proposition indicates that in order to prevent cross-purchasing, the monopolist increases the price of the lower quality versions and decreases the price of the higher quality versions. The intuition is that as the quality of the shared characteristics increases, the group-specific characteristics becomes relatively less a source of utility, and cross-purchasing from higher-taste groups to lower-quality (and priced) versions becomes more of a problem. Consequently, to prevent consumers from the highest taste group receiving greater utility net of price from the lowest priced information good than from the good that is customized for them, the monopolist increases the price of the lowest priced good to eliminate crosspurchasing - thereby maintaining the IC condition. For consumers in the lowest priced group fewer of them find it individually rational to purchase, and the proportion of that group which is served is reduced. In the case when the highest taste group is not covered that is, when not all consumers in the highest taste group purchase, downward adjustments also occur to the price of the good customized for the highest taste group, which in turn increases the proportion of consumers served from the highest taste group.

We denote $q_{a}^{I}=\frac{k_{i} \theta_{i}^{*}}{k_{h} \theta_{h}^{*}}$, where $\theta_{i}^{*}$ and $\theta_{h}^{*}$ are defined by (6). For $q_{a} \in\left[0, q_{a}^{I}\right)$, there is no interaction between segments $i$ and $h$ and two separate versions are offered to the corresponding segments.

For $q_{a} \geq q_{a}^{I}$, there are possible interactions between segments $i$ and $h$ where consumers in segment $h$ may find it better off purchasing version designed for segment $i$. Denote $\theta_{h}^{V}$ as

$$
\theta_{h}^{V}=\left\{\theta: \frac{1-\frac{q_{a}}{q_{h}} \theta_{i} f\left(\theta_{i}\right)-F(\theta)}{f(\theta)}=\theta\right\} .
$$

Situation I: $\theta_{h}^{V} \geq \theta_{h-1}$. It means with the increase in the shared characteristics, $\tilde{\theta}_{i}$ reaches its upper limit $\theta_{i}$ before $\tilde{\theta}_{h}$ gets to its lower limit $\theta_{h-1}$ and (5) is binding. Because the overall profit decreases with an increase in the quality of shared characteristics, there exists an $q_{a}^{H}$ so that $\Pi\left(\tilde{\theta}_{i}, \tilde{\theta}_{h}\right)=\Pi\left(\theta_{h}^{*}\right)$ where $\tilde{\theta}_{i}$ and $\tilde{\theta}_{h}$ are jointly determined by the first-order condition and the binding (5). 


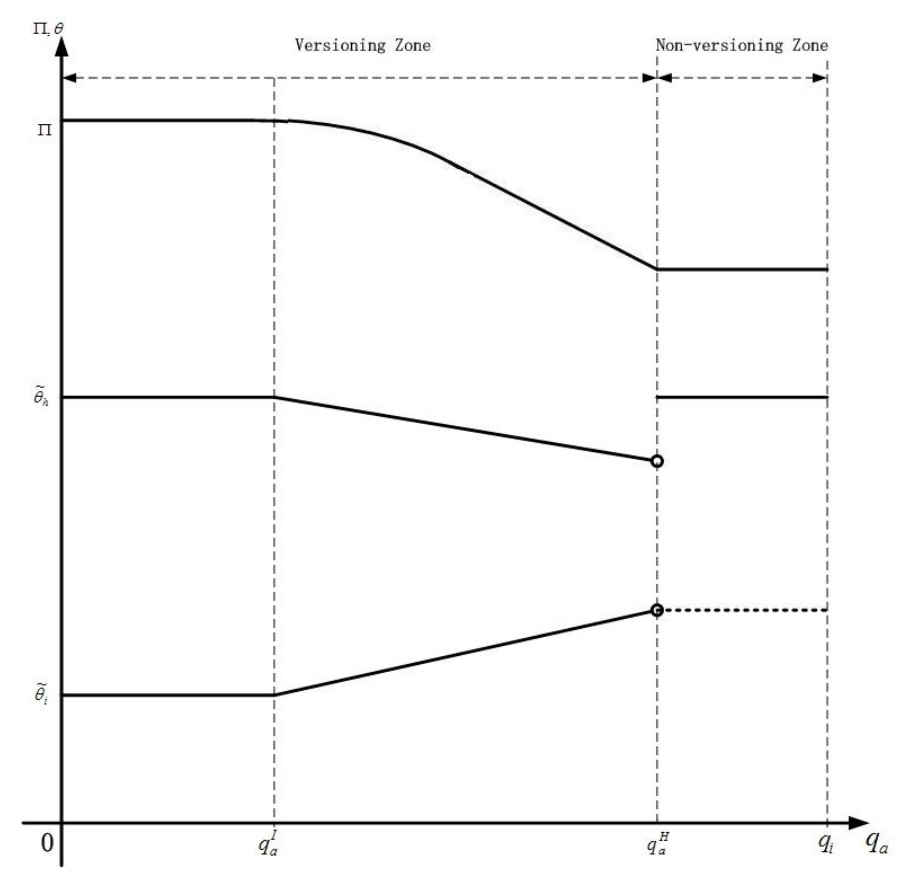

\section{Figure 2-1: Comparative Statics of Shared Characteristics $\left(\theta_{h}^{V} \geq \theta_{h-1}\right)$}

As illustrated in Figure 2-1, for $q_{a} \in\left[q_{a}^{I}, q_{a}^{H}\right)$, the monopolist still offers two versions with a shrinking market for the lower taste segment and an expanding market for the highest taste segment.

For $q_{a} \in\left[q_{a}^{H}, q_{i}\right], \Pi\left(\tilde{\theta}_{i}, \tilde{\theta}_{h}\right)<\Pi\left(\theta_{h}^{*}\right)$, which means with a further increase of the shared characteristics, the loss of profit from the high taste segment exceeds gains of profit from the lower taste segment. Thus, the monopolist removes version $q_{i}$ and versioning is not optimal.

Situation II: $\theta_{h}^{V}<\theta_{h-1}$. It means with the increase in the shared characteristics, $\tilde{\theta}_{h}$ gets to its lower limit $\theta_{h-1}$ before $\tilde{\theta}_{i}$ reaches its upper limit $\theta_{i}$. Denote $\theta_{i}^{V}$ such that

$$
\theta_{i}^{V}=\left\{\theta: \frac{1-F\left(\theta_{h-1}\right)+F\left(\theta_{i}\right)-F(\theta)}{f(\theta)}=\theta\right\},
$$

and denote $q_{a}^{V}$ such that

$$
q_{a}^{V}=\frac{k_{i} \theta_{i}^{V} q_{i}}{k_{h} \theta_{h-1}} .
$$

For $q_{a} \in\left[q_{a}^{I}, q_{a}^{V}\right)$, the monopolist increases the price of the lower taste version to maintain (5). Versions are offered to both segments. Because the overall profit decreases with an increase 
in the quality of shared characteristics, there exists an $q_{a}^{H}$ so that $\Pi\left(\theta_{i}^{V}, \theta_{h-1}\right)=\Pi\left(\theta_{h}^{*}\right)$.

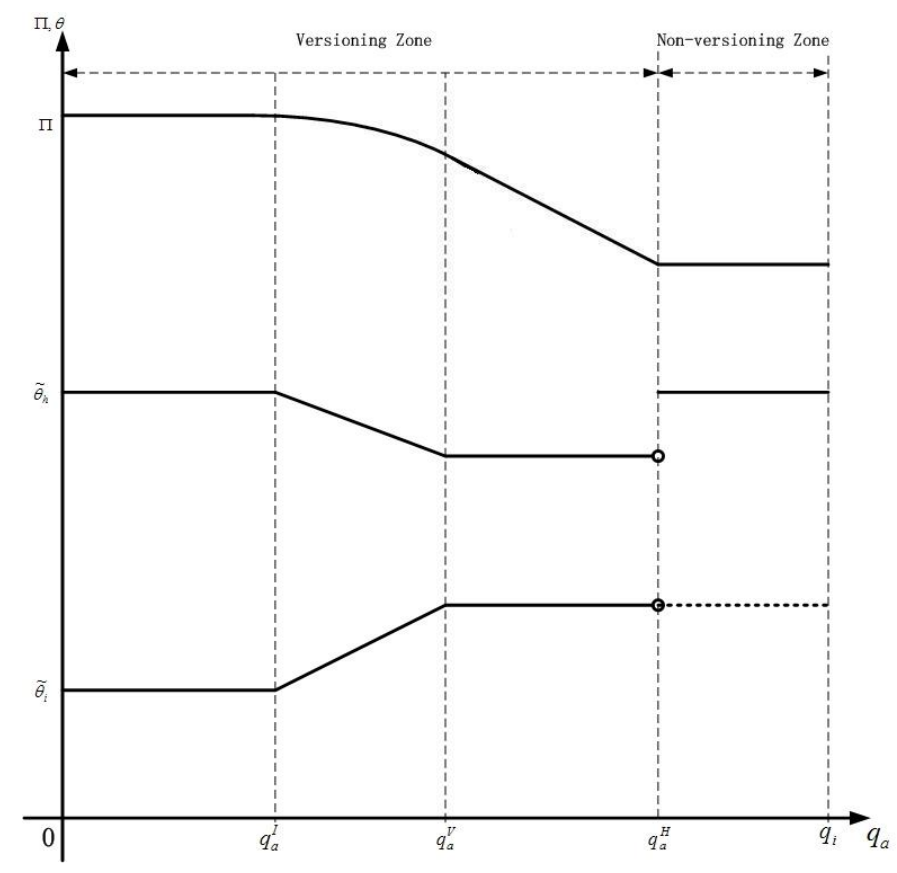

\section{Figure 2-2: Comparative Statics of Shared Characteristics $\left(\theta_{h}^{V}<\theta_{h-1}\right)$}

As illustrated in Figure 2-2, for $q_{a} \in\left[q_{a}^{V}, q_{a}^{H}\right)$, the monopolist maintains the price of the lower taste version and reduces the price of the higher taste version. (5) is violated and price of the high taste version is determined by the binding IC condition. Still two versions are offered.

For $q_{a} \in\left[q_{a}^{V}, q_{a}^{H}\right)$, the market share for both versions remain constant. That is because when (5) is no longer satisfied, the binding IC condition determines the prices. When the higher taste group is already covered, the total loss of profit from the high taste segment is less than if the monopolist shrinks the market of the lower version. Thus it is optimal to keep the price (thus the market share) of the lower taste version while lowering the price of the higher taste version.

For $q_{a} \in\left[q_{a}^{H}, q_{i}\right], \Pi\left(\theta_{i}^{V}, \theta_{h-1}\right)<\Pi\left(\theta_{h}^{*}\right)$, which means with further increase of the shared characteristics, the loss of profit in the high taste segment exceeds profits from the lower taste segment. Thus, the monopolist removes version $q_{i}$ and versioning is not optimal. 
From our comparative statics analysis we also find that profit (weakly) decreases with increases in the quality of the shared characteristics. That is because with increases of the shared characteristics, the threat of cross-purchasing is greater. The monopolist has to adjust the pricing of both versions that introduces an additional constraint to the profit maximization problem.

Our results suggest a monopolist may offer fewer versions than the number of distinct groups and this is frequently observed in practice. For example, although Kurzweil offers seven versions of its voice recognition software, it is far from covering all the potential groups in this market. Our model implies that the monopolist only provides customized versions to groups with high willingness to pay or with requirements that can be sufficiently differentiated from other groups so as to be able to satisfy IC conditions to prevent crosspurchasing.

\subsection{When Cross-purchasing Is Allowed}

In our model of utility with mutually exclusive characteristics, because the single-crossing condition where the marginal utility of taste is increasing in quality does not hold, the revelation principle is violated. Consequently, restricting cross-purchasing may be sub-optimal and allowing cross-purchasing may further increase the monopolist's profit. To make the scenario straightforward, we take any two groups $i$ and $j$ where $i<j$ into consideration.

When $q_{a} \leq \frac{k_{i} \theta_{i}^{*} q_{i}}{k_{j} \theta_{j}^{*}}$, where $\theta_{i}^{*}$ and $\theta_{j}^{*}$ are indifferent consumers in segments $i$ and $j$ when the segments are optimized separately, it is equivalent that $\frac{q_{a}}{q_{i}} \leq \frac{k_{i} \theta_{i}^{*}}{k_{j} \theta_{j}^{*}}$, which means there is no threat of cross-purchasing between segments $i$ and $j$ and these two segments can be treated separately and be offered a customized version for each group. Under this condition, where the IC condition is satisfied, our Theorem 1 is true regardless of whether cross-purchasing is allowed.

When $q_{a}>\frac{k_{i} \theta_{i}^{*} q_{i}}{k_{j} \theta_{j}^{*}}$, cross-purchasing occurs between segments $i$ and $j$. Here consumers from group $j$ cross-purchase the version customized for group $i$ as illustrated in the Figure 3 (consumers in a lower taste group never cross-purchase a version customized for the higher 
taste group).

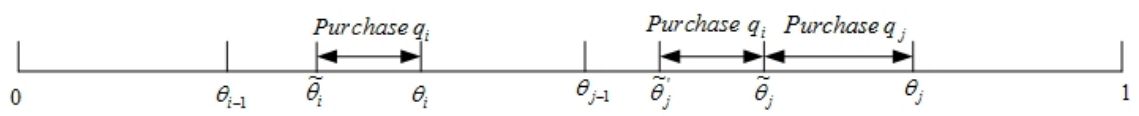

\section{Figure 3: When Cross-purchasing Is Allowed}

If there are consumers in group $j$ that purchase the good customized for group $i$, the monopolist changes the price constraints in both groups $i$ and $j$. We denote the type in group $j$ who is indifferent between buying goods $q_{i}$ and $q_{j}$ by $\tilde{\theta}_{j}$, and the indifferent type for group $i$ who is indifferent between buying good $q_{i}$ and not buying by $\tilde{\theta}_{i}$. Then the price constraints are:

$$
p_{i}=k_{i} \tilde{\theta}_{i} q_{i}, \quad \tilde{\theta}_{i} \in\left[\theta_{i-1}, \theta_{i}\right)
$$

and

$$
k_{j} \tilde{\theta}_{j} q_{j}-p_{j}=k_{j} \tilde{\theta}_{j} q_{a}-p_{i}, \text { for } \tilde{\theta}_{j} \in\left[\theta_{j-1}, \theta_{j}\right)
$$

In group $j$, there is another indifferent type which we denote as consumer type $\tilde{\theta}_{j}^{\prime}$, that is indifferent between purchasing $q_{i}$ and not. And we have the following additional relationship

$$
k_{j} \tilde{\theta}_{j}^{\prime} q_{a}=k_{i} \tilde{\theta}_{i} q_{i}, \text { for } \tilde{\theta}_{j}^{\prime} \in\left[\theta_{j-1}, \tilde{\theta}_{j}\right]
$$

Based on the constraints of $\tilde{\theta}_{j}^{\prime}$, we have $\tilde{\theta}_{j}^{\prime}=\max \left\{\frac{k_{i} q_{i} \tilde{\theta}_{i}}{k_{j} q_{a}}, \theta_{j-1}\right\}$ since $\tilde{\theta}_{j}^{\prime} \leq \tilde{\theta}_{j}$ can always be satisfied. We have three possible consumer groups. Consumers in $\left[\tilde{\theta}_{i}, \theta_{i}\right)$ that purchase $q_{i}$, consumers in $\left[\tilde{\theta}_{j}^{\prime}, \tilde{\theta}_{j}\right)$ that purchase $q_{i}$ and consumers in $\left[\tilde{\theta}_{j}, \theta_{j}\right)$ that purchase $q_{j}$. Consumers in $\left[\tilde{\theta}_{j}^{\prime}, \tilde{\theta}_{j}\right)$ are the market encroachment of $q_{i}$ in market for $q_{j}$. Thus, the monopolist's profit maximization problem is

$$
\begin{array}{r}
\max _{\tilde{\theta}_{i}, \tilde{\theta}_{j}}\left\{\Pi\left(\tilde{\theta}_{i}, \tilde{\theta}_{j}\right)=p_{i}\left[F\left(\theta_{i}\right)-F\left(\tilde{\theta}_{i}\right)\right]+p_{i}\left[F\left(\tilde{\theta}_{j}\right)-F\left(\tilde{\theta}_{j}^{\prime}\right)\right]+p_{j}\left[F\left(\theta_{j}\right)-F\left(\tilde{\theta}_{j}\right)\right]\right\} \\
\text { s.t. } \tilde{\theta}_{i} \in\left[\theta_{i-1}, \theta_{i}\right), \tilde{\theta}_{j} \in\left[\theta_{j-1}, \theta_{j}\right), \tilde{\theta}_{j}^{\prime}=\max \left\{\frac{k_{i} q_{i} \tilde{\theta}_{i}}{k_{j} q_{a}}, \theta_{j-1}\right\} .
\end{array}
$$


Substituting the price relationships (10) and (11) into the profit maximization model, we get

$$
\begin{gathered}
\max _{\tilde{\theta}_{i}, \tilde{\theta}_{j}}\left\{\Pi\left(\tilde{\theta}_{i}, \tilde{\theta}_{j}\right)=k_{i} \tilde{\theta}_{i} q_{i}\left[F\left(\theta_{i}\right)-F\left(\tilde{\theta}_{i}\right)+F\left(\theta_{j}\right)-F\left(\tilde{\theta}_{j}^{\prime}\right)\right]+k_{j} \tilde{\theta}_{j}\left[q_{j}-q_{a}\right]\left[F\left(\theta_{j}\right)-F\left(\tilde{\theta}_{j}\right)\right]\right\} \\
\text { s.t. } \tilde{\theta}_{i} \in\left[\theta_{i-1}, \theta_{i}\right), \tilde{\theta}_{j} \in\left[\theta_{j-1}, \theta_{j}\right), \tilde{\theta}_{j}^{\prime}=\max \left\{\frac{k_{i} q_{i} \tilde{\theta}_{i}}{k_{j} q_{a}}, \theta_{j-1}\right\} .
\end{gathered}
$$

From the first-order conditions with respect to $\tilde{\theta}_{j}$ we have $\tilde{\theta}_{j}=\frac{F\left(\theta_{j}\right)-F\left(\tilde{\theta}_{j}\right)}{f\left(\tilde{\theta}_{j}\right)}$. Solving we get $\tilde{\theta}_{j}=\theta_{j}^{*}$, which means the market share for $q_{j}$ is the same regardless of whether there is a threat from $q_{i}$.

Now we come to the market share for $q_{i}$ in market segment $i$ and there are two situations.

1. If segment $j$ is not covered, then we have $\theta_{j-1}<\frac{k_{i} q_{i} \tilde{\theta}_{i}}{k_{j} q_{a}}<\theta_{j}^{*}$. Thus, we get $\tilde{\theta}_{j}^{\prime}=\frac{k_{i} q_{i} \tilde{\theta}_{i}}{k_{j} q_{a}}$. The first-order condition with respect to $\tilde{\theta}_{i}$ is

$$
\tilde{\theta}_{i}=\frac{F\left(\theta_{i}\right)-F\left(\tilde{\theta}_{i}\right)+F\left(\theta_{j}\right)-F\left(\frac{k_{i} q_{i} \tilde{\theta}_{i}}{k_{j} q_{a}}\right)}{f\left(\tilde{\theta}_{i}\right)+\frac{k_{i} q_{i}}{k_{j} q_{a}} f\left(\frac{k_{i} q_{i} \tilde{\theta}_{i}}{k_{j} q_{a}}\right)} .
$$

Because $\frac{F\left(\theta_{j}\right)-F(\theta)}{f(\theta)}$ is non-increasing in $\theta$ and $\frac{k_{i} q_{i} \tilde{\theta}_{i}}{k_{j} q_{a}}<\theta_{j}^{*}$, then $F\left(\theta_{j}\right)-F\left(\frac{k_{i} q_{i} \tilde{\theta}_{i}}{k_{j} q_{a}}\right)-$ $\frac{k_{i} q_{i} \tilde{\theta}_{i}}{k_{j} q_{a}} f\left(\frac{k_{i} q_{i} \tilde{\theta}_{i}}{k_{j} q_{a}}\right)>0$. Consequently, we have $F\left(\theta_{i}\right)-F\left(\tilde{\theta}_{i}\right)-\tilde{\theta}_{i} f\left(\tilde{\theta}_{i}\right)<0$. Because $\frac{F\left(\theta_{i}\right)-F(\theta)}{f(\theta)}$ is non-increasing in $\theta$, we have $\tilde{\theta}_{i}<\theta_{i}^{*}$. It means the proportion of group $i$ that is served is reduced with an increase in shared characteristics.

2. If segment $j$ is already covered by $q_{j}$, or if we have $\frac{k_{i} q_{i} \tilde{\theta}_{i}}{k_{j} q_{a}} \leq \theta_{j-1}$, which means market segment $j$ is jointly covered by $q_{i}$ and $q_{j}$, then we have $\tilde{\theta}_{j}^{\prime}=\theta_{j-1}$. The first order condition with respect to $\tilde{\theta}_{i}$ is:

$$
\tilde{\theta}_{i}=\frac{F\left(\theta_{i}\right)-F\left(\tilde{\theta}_{i}\right)+F\left(\theta_{j}\right)-F\left(\theta_{j-1}\right)}{f\left(\tilde{\theta}_{i}\right)} .
$$

Because $F\left(\theta_{j}\right)-F\left(\theta_{j-1}\right)>0$, we get that $F\left(\theta_{i}\right)-F\left(\tilde{\theta}_{i}\right)-\tilde{\theta}_{i} f\left(\tilde{\theta}_{i}\right)<0$. Because $\frac{F\left(\theta_{i}\right)-F(\theta)}{f(\theta)}$ is non-increasing in $\theta$, we have $\tilde{\theta}_{i}<\theta_{i}^{*}$. It means the proportion of group $i$ that is served is reduced with an increase in shared characteristics.

For both situations, when the quality from shared characteristics is a sufficiently large proportion of total quality so there is threat of cross-purchasing, an increase in the quality of the 
shared characteristics reduces the proportion of the lower taste group that is served. This effectively validates our Proposition 1.

Thus, whether we allow cross-purchasing or not, the versioning results in our Theorem 1 and Proposition 1 remain the same.

An increase in the quality of the shared characteristics $q_{a}$ lowers the overall profit of the monopolist. When $q_{a}$ reaches a point when the monopolist makes higher profit by serving the higher taste group $j$ only, then versioning is no longer optimal. The comparative statics of shared characteristics are similar to our scenario when cross-purchasing is not allowed.

\subsection{No Cross-Purchasing vs. Cross-Purchasing}

To compare scenarios when cross-purchasing is allowed and when it is not, we provide a numerical example in the on-line Appendix that illustrates the differences. As the numerical example shows, at lower and higher proportions of shared characteristics, the monopolist's versioning strategies as well as optimal profits are the same under both scenarios. For intermediate proportions of shared characteristics cross-purchasing does increase the monopolist's profits as it effectively removes a constraint - the IC condition. Our numerical example shows that the increase in profits from cross-purchasing are less than $2 \%$, and for most proportions of shared characteristics are less than $1 \%$.

More importantly, we take that the monopolist already knows the consumer groups in the market prior to the design of the information good. Consequently, during development versions are designed for the different groups with the purpose that consumers in any particular group receive value from features that are specific to that particular group (Ullah et al. 2010). For example, the medical features in Kurzweil's Voice Med are specific to, and provide value for, medical officials such as physicians well beyond the value form shared characteristics. Therefore, information goods are designed and targeted for separate market segments such that cross-purchasing rarely occurs. 


\section{Hierarchical Characteristics and Vertical Differenti- ation}

Here we examine versioning when different groups of consumers have utility with hierarchical characteristics as per our Assumption 4. The key feature is that lower taste groups do not value features designed for higher taste groups. However, a consumer in a higher taste group receives full value from features designed for lower taste groups. In our Windows 7 example, server functionality in the Professional edition is not valued by home users, and multiple-display and distributed cache in the Ultimate edition are not valued by power users but are valued by enterprise users. Even the more restricted functionality of the Home Premium edition are valued by power and enterprise users, and the server functionality of the Professional edition is valued by enterprise users.

The monopolist chooses the number of versions to offer through its choice of indifferent consumers in each group to maximize its profits as per (3). From our Assumption 4, we derive the following lemma.

Lemma 1 For a lower taste group to be provided with an information good customized for it, all higher taste groups must be covered and there is no cross-purchasing among different groups.

From Lemma 1, except for the lowest taste group that is served, all other groups that are served must be covered - that is, all consumers in the higher taste groups purchase. Suppose $i$ is the lowest taste group that is served. Then only the price for the lowest taste group, $p_{i}$, is determined by the binding IR condition. The price for all the higher taste groups, $p_{n}$ for $n>i$, is determined by the binding IC conditions. In the Windows 7 example, focusing on the three widely available versions, Lemma 1 means that the monopolist sets the prices of the Professional and Ultimate editions based on restricting cross-purchasing so that even the lowest taste enterprise user prefers the Ultimate edition to the Professional and Home Premium editions, and all power users prefer the Professional edition to either the lower quality Home Premium edition or the higher quality Ultimate edition. 
Using Lemma 1 in the on-line Appendix we derive the optimal indifferent consumer, $\tilde{\theta}_{e}$, where $e$ is the lowest taste group that is served. Given that group $e$ refers to the group in which the interior solution to the monopolist's profit maximization occurs, if the optimal indifferent consumer $\tilde{\theta}_{e}$ belongs to the highest taste group, $\tilde{\theta}_{e} \in\left[\theta_{h-1}, \theta_{h}\right)$, then the monopolist provides only one version of the information good. Otherwise, the monopolist may provide up to $h-e+1$ versions. Below is our versioning theorem for utility with hierarchical characteristics.

Theorem 2 (Versioning for Utility with Hierarchical Characteristics) A necessary and sufficient condition for multiple versions is that $k_{h} \theta_{h-1}\left[1-F\left(\theta_{h-1}\right)\right]$ is not the largest among $k_{e} \tilde{\theta}_{e}\left[1-F\left(\tilde{\theta}_{e}\right)\right]$ and $k_{i} \theta_{i-1}\left[1-F\left(\theta_{i-1}\right)\right]$ where $e<i \leq h$.

Theorem 2 is stated in terms of exogenous parameters, and can be verified by relatively straightforward calculations in practice. Due to the hierarchical structure of our Assumption 4, the versioning condition in Theorem 2 is independent of quality. Consequently, the theorem depends only on consumer preferences, partially separating the versioning decision from the decision of how to design the customized versions. Theorem 2 clearly shows that group taste plays an important role in versioning. Because $\theta[1-F(\theta)]$ decreases with $\theta$ when $\theta>\tilde{\theta}_{e}$, as long as the group taste of the highest taste group and that of the lower taste groups are sufficiently close, versioning is more likely to be optimal. Otherwise, the monopolist would offer the highest quality version only to ensure high profits from the highest taste group. In terms of our example of Windows 7, it means that whether versioning occurs depends on the relative differences in the preferences of different groups of users - enterprise, power or home users.

Although the condition in Theorem 2 ensures versioning, it does not ensure that each group is offered a customized version. If there are multiple groups that satisfy the sufficient condition for multiple versions in Theorem 2, then the monopolist still has to decide whether to offer a customized version for each of those groups. We derive a condition for the monopolist to decide whether to customize a version for a specific group. 
Proposition 2 The necessary and sufficient condition for group e to be provided with a separate version is that $k_{e} \tilde{\theta}_{e}\left[1-F\left(\tilde{\theta}_{e}\right)\right]$ is higher than any $k_{i} \theta_{i-1}\left[1-F\left(\theta_{i-1}\right)\right]$ where $e<i \leq h$. The necessary and sufficient condition for group $g>e$ to be provided with a separate version is that $k_{g} \theta_{g-1}\left[1-F\left(\theta_{g-1}\right)\right]$ is higher than any $k_{i} \theta_{i-1}\left[1-F\left(\theta_{i-1}\right)\right]$ where $g<i \leq h$.

Proposition 2 also depends on exogenous parameters only, and can be verified through straightforward calculations in practice. Proposition 2 implies that the highest quality version $q_{h}$ is customized for the highest taste group $h$ only. $\tilde{\theta}_{e}$ and $\theta_{g-1}$ are actually the indifferent consumers in groups $e$ and $g>e$, respectively, should those groups be provided with a separate version. Consequently, Proposition 2 is equivalent to the statement that for any group $i$ to be provided with a separate version, the indifferent consumer $\tilde{\theta}_{i}$ has the highest value for $k \theta[1-F(\theta)]$ for $\theta \in\left[\tilde{\theta}_{i}, \theta_{h}\right]$. Following the same logic as discussed in Theorem 2, in order for $k \theta[1-F(\theta)]$ to be the highest for a lower taste group which makes the customized version optimal, the group taste of this lower taste group and that of the adjacent higher taste group should be sufficiently close. If conditions in Proposition 2 cannot be satisfied for a specified group, then this group is either not served at all, or served with the same version as a lower taste group. Thus, Proposition 2 provides a means to determine how many versions are offered.

\section{Conclusions}

We investigated conditions that determine when an information goods monopolist chooses to implement versioning strategies, and showed that versioning strategies can be implemented if different groups of consumers can be clearly defined. In other words, versioning strategies must fit existing market segments. This result is more evident when consumers have utility with hierarchical characteristics as the versioning condition is based only on features of consumer tastes. Our conditions are consistent with Shapiro and Varian's (1999) suggestion that versions should be customized to accentuate the differences in tastes between groups.

We have shown that for utility with mutually exclusive characteristics, versioning is possible when the quality (hence, value) of shared characteristics is sufficiently low so that 
cannibalization from a lower version can be covered by its revenue increase. When the value of shared characteristics is relatively higher, the monopolist shrinks the market share for the lower-taste group by raising the price of the lower-quality version to effectively reduce the cannibalization of profits from the higher-quality version. Ultimately the process of increasing the value of shared characteristics results in a single version being optimal. In the case of utility with hierarchical characteristics, we derive a condition that determines when versioning occurs, and this condition only depends on consumer preferences. We further derive conditions under which a version is customized for each group. Deriving conditions under which a version is customized for each group allows us to determine when versioning is optimal and, if so, how many versions should be offered.

Comparing our model with that of Lacourbe et al. (2009), with development intensive products where variable costs are effectively zero (e.g., software), they find that pure vertical differentiation (quality) is never optimal - echoing the monopolist one-version result. Moreover, a monopolist with many products only differentiates in the horizontal dimension whereas price and quality remain the same over the different versions. This is closely related to our utility with mutually exclusive characteristics where the characteristics differ over the feature space, and versioning is based on the feature space. In contrast to our results, they find that vertical differentiation occurs only when variable costs are present, whereas we obtain versioning from our utility with hierarchical characteristics which effectively defines vertical differentiation by increasingly broadening the characteristics to which the individual and group taste applies. Indeed, our utility with hierarchical characteristics creates a discontinuous vertical dimension that is distinct from Vandenbosch and Weinberg (1995), Lacourbe et al. (2009), and others where the vertical dimension of preferences is continuous as a variable in an additive utility function.

Although we assume that the value of the group taste component of preferences increases with increasing segments of individual taste, for the most part our results hold as we demonstrated when the group taste component is equal in value across individual tastes. The value of the group taste component being equal across individual tastes is distinct from group tastes being the same across individual tastes, as the former continues to allow our 
assumptions of utility with mutually exclusive characteristics and of utility with hierarchical characteristics to be operationalized as in our analysis. Equal group tastes also decreases the gaps between consumer segments in Figure 1.

Contributions and Managerial Insights Our contributions lie in two aspects, and are based on preferences that includes individual and group tastes. First, most of the previous research on information goods versioning (Bhargava and Choudhary 2001, Jones and Mendelson 2011, Jing 2007, Wu and Chen 2008) uses vertical differentiation. In contrast, we treat information goods as a combination of characteristics, and in doing so we can analyze horizontal differentiation and vertical differentiation under the same modeling framework based on group tastes. Second, as we described in the Introduction, in order to show when multiple versions rather than a single version is optimal many researchers have needed additional elements in their models such as network externalities and anti-piracy. Our approach has been to work through refinements of the utility function to obtain optimal solutions where multiple versions are used rather than adding model elements.

Our theorems and propositions are characterized using parameters that are exogenous to the model, meaning that the conditions of our theorems and propositions can be checked in practice to determine when versioning is beneficial. Our results using mutually exclusive characteristics whereby different consumers prefer different subsets of features suggests that any small horizontal differentiation in product line design can potentially support versioning. Consequently, the separation between shared and mutually exclusive characteristics in design has versioning implications (Ullah et al. 2010). Our definition using hierarchical characteristics is a specific case of vertical differentiation that increasingly broadens the characteristics to which the individual and group taste applies, which is common in practice whereby some consumers simply want more features. Our results here can determine which groups of consumers should be provided with separate versions and which should not, again with design having implications on versioning. 
Limitations To concentrate on development intensive goods, we assumed zero versioning costs. If versioning costs are significant, then these costs may reduce the number of versions offered. If costs of offering an extra version are higher than the incremental profits, then the monopolist simply removes this version (Bhargava and Choudhary 2008).

Our modeling results are based on assumptions of multiplicative utility and a positive relationship between group taste and individual taste. Together, these impose significant structure on consumer preferences. The latter relationship embodies a strong-ordering assumption whereby the group taste component of preferences is increasing in individual taste for quality. This strong-ordered group taste component of preferences is necessary for our results - a mix of group and individual taste components without a similar structure would lead to a differently-scaled individual taste model with unsystematic discontinuities, and our results would not hold without further assumptions.

Comparing our model to the classic work of Maskin and Riley (1984) that in the context of quality differentiation results in versioning for industrial goods, there are two critical differences. The first is on the cost side whereby they assume convex costs of quality so that each quality level has a cost such that versions have variable costs proportional to quality which is critical to their versioning result, as opposed to our implicit assumption that the highest quality information good (flagship version) has already been developed (at some fixed cost) and our explicit assumption that versioning costs (hence variable costs) are zero. The second is on the utility side where Maskin and Riley suppose that the implied demand curves can be characterized through a single parameter representing individual taste, whereas the aspect that is essential to our versioning results is a second parameter representing group taste with mutually exclusive or hierarchical characteristics.

Future research may relax some of the assumptions we make, and address additional issues. For example, using network externalities, Cheng and Tang (2010) explore conditions under which a free trial version is offered, whereas in our model - that does not include network externalities - the lower quality version has a non-zero price. Including network externalities in our model may explain the existence of free trial version. Dogan et al. (2010) consider versioning in a two-period model where a lower-quality version is provided in the first 
period with the possibility of upgrade in the second period. Wei and Nault (2012) consider a two-stage model with multiple versions and uncertain quality where consumers that choose a lower-quality version in the first stage may learn from experience and upgrade in the second stage. In the latter model, the low quality version can be offered for free. Similarly, Niculescu and Wu (2013) also develop a two-period framework accounting for both word-ofmouth effects and experience-based learning to explore the economics of free. In contrast, our analysis only examines versioning in a single period. Previous research (Ghose et al. 2006) demonstrates empirically that in the Internet-based book market used-book sales cannibalize new-book purchases at least to some extent, and increase welfare through the expansion of total market sales. There is no similar empirical research on cannibalization or increases in total sales and social welfare when information goods are versioned.

Competition can potentially make a significant difference in versioning strategies. As discussed in Johnson and Myatt (2003), firms may alter their versioning strategy when facing competition either through product line pruning or introducing low-end brands. Research examining versioning and competition in the context of information goods includes Jones and Mendelson (2011) and Wei and Nault (2006).

\section{Acknowledgement}

The authors gratefully acknowledge helpful comments from Cheryl Gaimon, the senior editor and three anonymous reviewers, Vidyanand Choudhary, Albert Dexter, Victoria Mitchell, participants of WISE 2005, INFORMS CIST 2006, the NYU/CeDER 2006 Summer Workshop on the Economics of Information Technology, the UofA/UofC MIS Research Workshop, and seminar participants from Graduate School of Business of Stanford University, Graduate School of Management of University of California at Davis and Guanghua School of Management of Peking University for helpful comments on a precursor to this paper, titled "Product Differentiation and Market Segmentation of Information Goods". We thank the Natural Science and Engineering Research Council of Canada, the Social Science and Humanities Research Council of Canada, the David B. Robson Endowment and the iRC at the Haskayne School of Business at the University of Calgary, the National Natural Sci- 
ence Foundation of China (Project 71272077), and the E-Commerce Research Center at the School of Management at Fudan University for support.

\section{References}

Bakos, Y., and E. Brynjolfsson. 1999. Bundling Information Goods: Pricing, Profits, and Efficiency. Management Sci. 45(12) 1613-1630.

Bhargava, H. K., and V. Choudhary. 2001. Information Goods and Vertical Differentiation. J. Management Inform. Systems 18(2) 89-106.

Bhargava, H. K., and V. Choudhary. 2008. When is Versioning Optimal for Information Goods? Management Sci. 54(5) 1029-1035.

Birk, A., G. Heller, I. John, K. Schmid, T. von de Maben and K Muller. 2003. Product Line Engineering: the State of the Practice. IEEE Software November/December 52-60.

Bonatti, A. 2008. Brand-Specific Tastes for Quality. Working Paper, Yale University.

Canoy, M., and M. Peitz. 1997. The Differentiation Triangle. J. of Industrial Econ. XLV(3) 305-328.

Caplin, A.S., and B.J. Nalebuff. 1986. Multi-Dimensional Product Differentiation and Price Competition. Oxford Economic Papers. 129-145.

Chellappa, R.K., and S. Shivendu. 2005. Managing Piracy: Pricing and Sampling Strategies for Digital Experience Goods in Vertically Segmented Markets. Inform. Systems Res. 16(4) 400-417.

Chen, Y., and S. Seshadri. 2007. Product Development and Pricing Strategy for Information Goods under Heterogeneous Outside Opportunities. Inform. Systems Res. 18(2) 150-172.

Cheng, H.K., and Q.C. Tang. 2010. Free Trial or No Free Trial: Optimal Software Product Design with Network Effects. European J. of Operational Res. 205(2) 437-447.

Choudhary, V. 2010. Use of Pricing Schemes for Differentiating Information Goods. Inform. Systems Res. 21(1) 78-92. 
Corstjens, M., and R. Lal. 2000. Building Store Loyalty Through Store Brands. J. of Marketing Res. 281-291.

Cottrell, T., and B.R. Nault. 2004. Product Variety and Firm Survival in the Microcomputer Software Industry. Strat. Manag. J. 25, 1005-1025.

Dogan, K., Y. Ji, V. S. Mookerjee and S. Radhakrishnan. 2010. Managing the Versions of a Software Product under Variable and Endogenous Demand. Inform. Systems Res. Articles in Advance, 1-19.

Frank, R. E., W. F. Massy, and Y. Wind. 1972. Market Segmentation. Prentice-Hall, Inc., Englewood Cliffs, New Jersey.

Fudenberg, D., and J. Tirole. 1991. Game Theory. MIT Press, Cambridge.

Geng, X., M.B. Stinchcombe, and A.B. Whinston. 2005. Bundling Information Goods of Decreasing Value. Inform. Systems Res. 51 (4) 662-667.

Ghose, A., M. Smith, and R. Telang. 2006. Internet Exchanges for Used Books: An Empirical Analysis of Product Cannibalization and Welfare Impact. Inform. Systems Res. 17(1) 3-19.

Ghose, A., and A. Sundararajan. 2005. Software versioning and quality degradation? An exploratory study of the evidence. Working paper, New York University, New York.

Jing, B. 2007. Network Externalities and Market Segmentation in a Monopoly. Economics Letters., 95 (2007) 7-13.

Johnson, J.P., and D.P. Myatt. 2003. Multiproduct Quality Competition: Fighting Brands and Product Line Pruning. American Economic Review. 93(3) 748-774.

Jones, R., and H. Mendelson. 2011. Information Goods vs. Industrial Goods: Cost Structure and Competition. Management Sci. 57(1) 164-176.

Lacourbe, P., C.H. Loch, and S. Kavadias. 2009. Product Positioning in a Two-Dimensional Market Space. Production and Operations Management. 18(3) 315-332.

Maskin, E., and J. Riley. 1984. Monopoly With Incomplete Information. RAND Journal of 
Economics. 15(2) 173-196.

Moorthy, K.S. 1984. Market Segmentation, Self-Selection, and Product Line Design. Marketing Sci. 3(4) 288-301.

Nault, B.R., 1997. Quality Differentiation and Adoption Costs: The Case for Interorganizational Information Systems Pricing. Annals of Operations Res. 71 115-142.

Niculescu, M.F., and D.J. Wu. 2013. Economics of Free Under Perpetual Licensing: Implications for the Software Industry. Available at SSRN: http://ssrn.com/abstract=1853603 or http://dx.doi.org/10.2139/ssrn.1853603.

Rosen, S. 1974. Hedonic Prices and Implicit Markets: Product Differentiation in Pure Competition. J. Political Econ. 82(1) 34-55.

Shapiro, C., and H. R. Varian. 1999. Information Rules. Harvard Business School Press, Boston.

Sultan, F., and L. Chan. 2000. The Adoption of New Technology: The Case of ObjectOriented Computing in Software Companies. IEEE Transactions on Engineering Management. 47(1) 106-126.

Sundararajan, A. 2004. Nonlinear Pricing of Information Goods. Management Sci. 50(12) 1660-1673.

Ullah, M.I., X. Wei, B.R. Nault and G. Ruhe. 2010. Balancing Business and Technical Objectives for Supporting Software Product Evolution. International Journal of Software Engineering and Computing. 2 (2) 75-93.

Vandenbosch, M.B., and C.B Weinberg. 1995. Product and Price Competition in a TwoDimensional Vertical Differentiation Model. Marketing Sci. 14(2) 224-249.

Varian, H. R. 1998. Versioning information goods. D. Hurley, B. Kahin, H. R. Varian, Eds. Internet Publishing and Beyond. MIT Press, Boston.

Varian, H. R. 2000. Buying, Sharing and Renting Information Goods. Journal of Industrial Economics. 48(4) 473-488. 
Wei, X., and B.R. Nault. 2006. Vertically Differentiated Information Goods: Entry Deterrence, Rivalry Clear-out or Coexistence. Proceedings of the 2006 INFORMS Conference on Information Systems and Technology. Pittsburgh.

Wei, X., and B.R. Nault. 2012. Experience Information Goods: "Version-to-Upgrade". Decision Support Systems. Forthcoming, http://dx.doi.org/10.1016/j.dss.2012.11.006.

Wu, S. and P. Chen. 2008. Versioning and Piracy Control for Digital Information Goods. Operations Research. 56(1) 157-172.

\section{On-Line Appendix}

\section{A.1. Proof of Theorem 1}

Proof. For $\frac{q_{a}}{q_{n}}<\frac{k_{n} \theta_{n}}{k_{h} \theta_{h}^{*}}$, we define the indifferent consumer $\tilde{\theta}_{n}=\max \left\{\theta_{n-1}, \frac{k_{n} \theta_{h}^{*} q_{a}}{k_{n} q_{n}}\right\}$. Because $\tilde{\theta}_{n}<\theta_{n}$, the monopolist can safely set $p_{n}=k_{n} \tilde{\theta}_{n} q_{n}$ to offer $q_{n}$ to segment $n$ without impacting the profit gained from segment $h$. Thus at least two versions $q_{h}$ and $q_{n}$ should be offered.

\section{A.2. Proof that $\frac{F\left(\theta_{n}\right)-F(\theta)}{f(\theta)}$ is non-increasing in $\theta$ for $\theta \in\left[\theta_{n-1}, \theta_{n}\right)$}

Firstly we define functions $G(\theta)=\frac{F\left(\theta_{n}\right)-F(\theta)}{f(\theta)}$ and $H(\theta)=\frac{1-F(\theta)}{f(\theta)}$. From Assumption 1, we know the inverse hazard function is non-increasing, so that

$$
H^{\prime}(\theta)=-\frac{[f(\theta)]^{2}+[1-F(\theta)] f^{\prime}(\theta)}{[f(\theta)]^{2}} \leq 0
$$

The first derivative of $G(\theta)$ with respect to $\theta$ is

$$
G^{\prime}(\theta)=-\frac{[f(\theta)]^{2}+\left[F\left(\theta_{n}\right)-F(\theta)\right] f^{\prime}(\theta)}{[f(\theta)]^{2}} .
$$

For $f^{\prime}(\theta) \geq 0$, it is straightforward that $G^{\prime}(\theta) \leq 0$ because $F\left(\theta_{n}\right)-F(\theta) \geq 0$ for $\theta \in\left[\theta_{n-1}, \theta_{n}\right)$.

For $f^{\prime}(\theta)<0$, because $F\left(\theta_{n}\right) \leq 1$, we get

$$
G^{\prime}(\theta)=-\frac{[f(\theta)]^{2}+\left[F\left(\theta_{n}\right)-F(\theta)\right] f^{\prime}(\theta)}{[f(\theta)]^{2}} \leq-\frac{[f(\theta)]^{2}+[1-F(\theta)] f^{\prime}(\theta)}{[f(\theta)]^{2}} \leq 0 .
$$

Thus we get that for both situations, $G^{\prime}(\theta) \leq 0$. It means $\frac{F\left(\theta_{n}\right)-F(\theta)}{f(\theta)}$ is non-increasing in $\theta$ for $\theta \in\left[\theta_{n-1}, \theta_{n}\right)$. 


\section{A.3. Proof of Proposition 1}

Consider an increase in the quality of the shared characteristics when the IC condition is binding. Denote the lowest priced group as $i$. To maintain the (binding) IC condition, the monopolist changes prices in both groups $i$ and $h$. From (4), $\tilde{\theta}_{h}$ is the consumer in group $h$ that is indifferent between purchasing goods $q_{h}$ and $q_{i}$, and from (1) $\tilde{\theta}_{i}$ is the consumer in group $i$ that is indifferent between purchasing good $q_{i}$ and not purchasing. Depending on whether the highest taste group $h$ is covered - that is, whether all consumers in the highest taste group purchase, there are two cases.

\section{Case 1: Group h Is Not Covered}

In this case IR binds at $\tilde{\theta}_{i}<\theta_{i}$ and $\tilde{\theta}_{h}>\theta_{h-1}$. Substituting (1) [IR] and (2) [IC] into (3), only considering groups $i$ and $h$, we have

$\max _{\tilde{\theta}_{i}, \tilde{\theta}_{h}} \Pi\left(\tilde{\theta}_{i}, \tilde{\theta}_{h}\right)=\max _{\tilde{\theta}_{i}, \tilde{\theta}_{h}}\left\{k_{i} \tilde{\theta}_{i} q_{i}\left[F\left(\theta_{i}\right)-F\left(\tilde{\theta}_{i}\right)\right]+k_{h} \tilde{\theta}_{h} q_{h}\left[1-F\left(\tilde{\theta}_{h}\right)\right]\right\}$ s.t. $\tilde{\theta}_{i} \in\left[\theta_{i-1}, \theta_{i}\right), \tilde{\theta}_{h} \in\left[\theta_{h-1}, \theta_{h}\right)$.

From the first-order condition with respect to $\tilde{\theta}_{i}$, recognizing that changes in $\tilde{\theta}_{i}$ affect $\tilde{\theta}_{h}$ through the IC condition, we have

$$
q_{a}\left[F\left(\theta_{i}\right)-F\left(\tilde{\theta}_{i}\right)-\tilde{\theta}_{i} f\left(\tilde{\theta}_{i}\right)\right]+q_{h}\left[1-F\left(\tilde{\theta}_{h}\right)-\tilde{\theta}_{h} f\left(\tilde{\theta}_{h}\right)\right]=0 .
$$

From the crossing point in (6), we know that $F\left(\theta_{i}\right)-F\left(\tilde{\theta}_{i}\right)-\tilde{\theta}_{i} f\left(\tilde{\theta}_{i}\right)=0$ when $\tilde{\theta}_{i}=\theta_{i}^{*}$, and that for $\theta_{h}$ we have $1-F\left(\tilde{\theta}_{h}\right)-\tilde{\theta}_{h} f\left(\tilde{\theta}_{h}\right)=0$ when $\tilde{\theta}_{h}=\theta_{h}^{*}$. Because both $\frac{F\left(\theta_{i}\right)-F(\theta)}{f(\theta)}$ and $\frac{1-F(\theta)}{f(\theta)}$ are non-increasing, we have $\tilde{\theta}_{i}>\theta_{i}^{*}$ and $\tilde{\theta}_{h}<\theta_{h}^{*}$.

Case 2: Group h Is Covered

In this case IR binds at $\tilde{\theta}_{i}<\theta_{i}$ only and the monopolist can only adjust $\tilde{\theta}_{i}$. Thus the monopolist's profit maximization is

$\max _{\tilde{\theta}_{i}} \Pi\left(\tilde{\theta}_{i}\right)=\max _{\tilde{\theta}_{i}}\left\{k_{i} \tilde{\theta}_{i} q_{i}\left[F\left(\theta_{i}\right)-F\left(\tilde{\theta}_{i}\right)\right]+\left[k_{h} \theta_{h-1}\left[q_{h}-q_{a}\right]+k_{i} \tilde{\theta}_{i} q_{i}\right]\left[1-F\left(\theta_{h-1}\right)\right]\right\}$ s.t. $\tilde{\theta}_{i} \in\left[\theta_{i-1}, \theta_{i}\right)$,

where the price of the highest taste good $k_{h} \theta_{h-1}\left[q_{h}-q_{a}\right]+k_{i} \tilde{\theta}_{i} q_{i}$ is obtained from the binding IC condition. From the first-order condition with respect to $\tilde{\theta}_{i}$, we have

$$
\left[F\left(\theta_{i}\right)-F\left(\tilde{\theta}_{i}\right)-\tilde{\theta}_{i} f\left(\tilde{\theta}_{i}\right)\right]+\left[1-F\left(\theta_{h-1}\right)\right]=0 .
$$

Because $F\left(\theta_{i}\right)-F\left(\tilde{\theta}_{i}\right)-\tilde{\theta}_{i} f\left(\tilde{\theta}_{i}\right)<0$, it follows that $\tilde{\theta}_{i}>\theta_{i}^{*}$. 


\section{A.4. Comparison of No Cross-purchasing with Cross-purchasing: A Numerical Example}

To compare the two scenarios when cross-purchasing is allowed and when it is not, we construct a numerical example. Suppose there are two groups of consumers in the market, and consumers are uniformly distributed across $[0,1]$. Consumers with individual taste $\theta$ in segments $[0,0.4)$ and $[0.4,1]$ belong to groups 1 , and 2 , respectively. The group tastes are $k_{1}=1$ and $k_{2}=2$. We set the quality of the two different versions to be the same, which is normalized to unity: $q_{1}=q_{2}=1$.

Figure A-1 shows when cross-purchasing is not allowed, how a monopolist's versioning strategies change with an increase in the quality of shared characteristics.

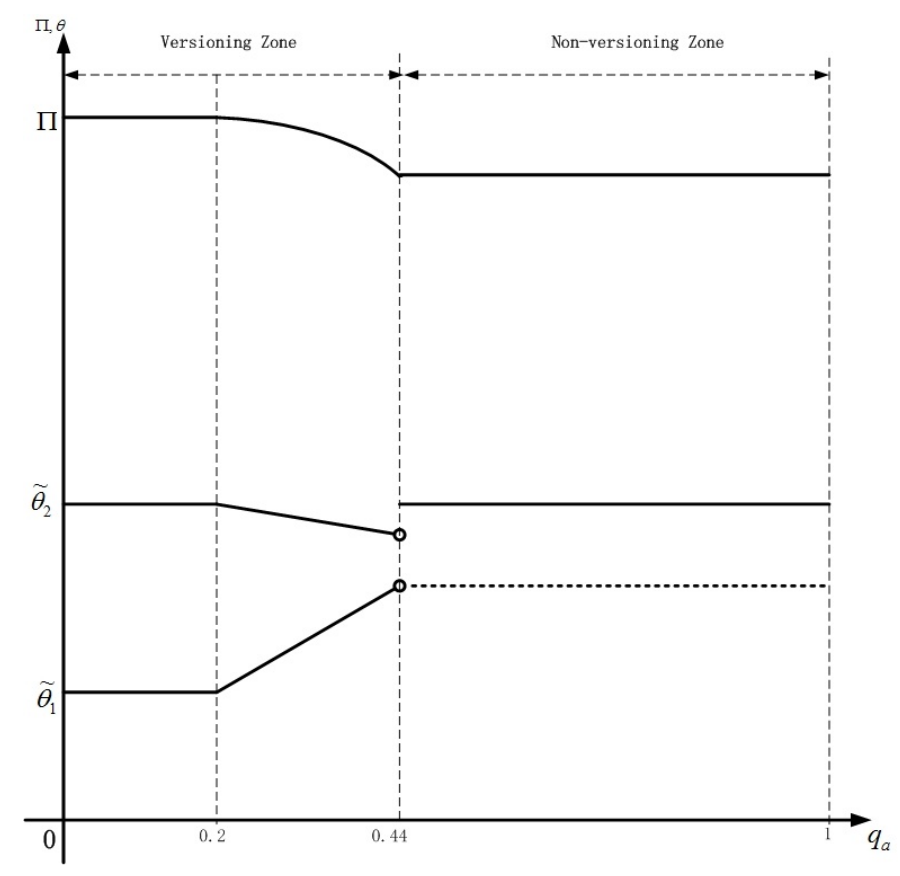

\section{Figure A-1: Example when Cross-purchasing Is Not Allowed}

In this scenario, for $0 \leq q_{a}<0.2$, the two groups are treated separately, two customized versions are offered, both groups 1 and 2 are partially covered. The total profit is the highest with two versions.

For $0.2 \leq q_{a}<0.44$, condition (5) binds and demand for the low taste group 1 shrinks while demand for the high taste group 2 expands. The total profit decreases with $q_{a}$. 
For $q_{a} \geq 0.44$, it is optimal for the monopolist to stop serving group 1 with a separate version and price is set so that only group 2 is served. Consequently, versioning is no longer optimal.

Figure A-2 shows when cross-purchasing is allowed, how a monopolist's versioning strategies change with an increase in the quality of shared characteristics.

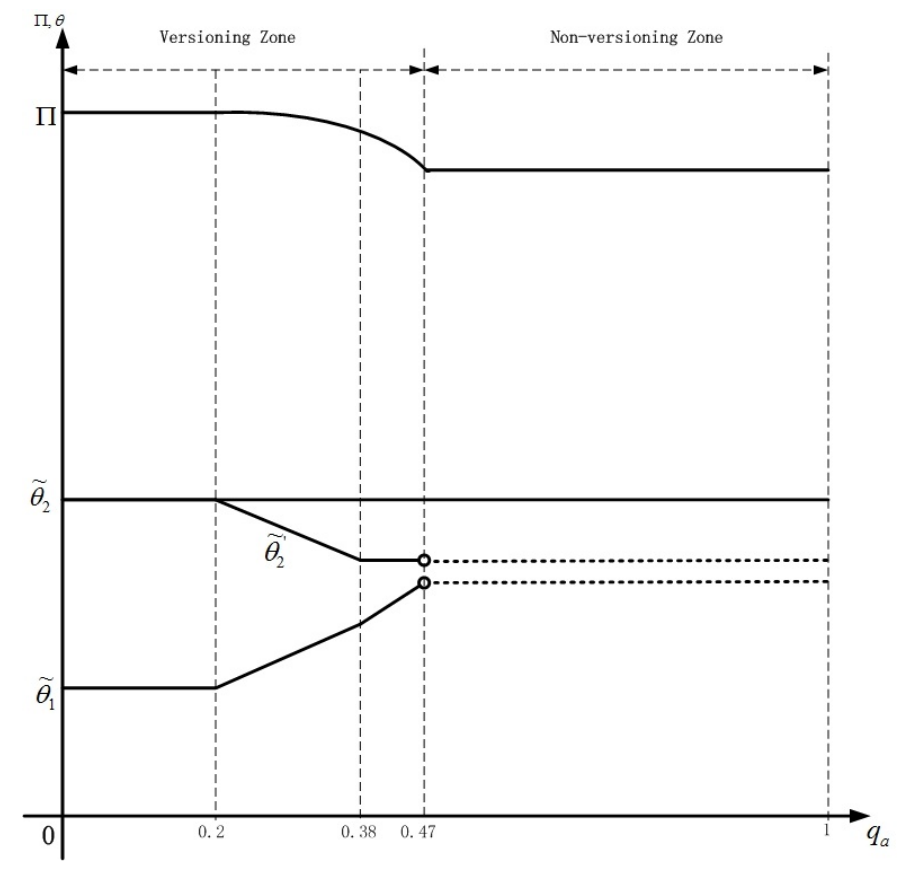

Figure A-2: Example when Cross-purchasing Is Allowed

In this scenario, for $0 \leq q_{a}<0.2$, the two groups are treated separately, which is exactly the same as the scenario when cross-purchasing is not allowed.

For $0.2 \leq q_{a}<0.38$, condition (5) binds and demand for the version customized for the low taste group 1 shrinks in its own segment while expands in the high taste group 2 . The market for the version customized for the high taste group 2 remains the same. Both groups are partially covered. The total profit decreases with $q_{a}$.

For $0.38 \leq q_{a}<0.47$, group 2 is covered while demand for the version customized for the low taste group 1 keeps shrinking in its own segment. Market for the version customized for the high taste group 2 remains the same. The total profit decreases with $q_{a}$. 
For $q_{a} \geq 0.47$, it is optimal for the monopolist to stop serving group 1 with a separate version and versioning is no longer optimal. It is also the same as the scenario when crosspurchasing is not allowed.

\begin{tabular}{|c|c|c|c|}
\hline $\begin{array}{c}\text { Shared } \\
\text { Characteristics }\end{array}$ & $\begin{array}{c}\text { Profit without Cross- } \\
\text { purchasing }\end{array}$ & $\begin{array}{c}\text { Profit with Cross- } \\
\text { purchasing }\end{array}$ & Profit Gap \\
\hline $0-0.2$ & 0.54 & 0.54 & 0 \\
\hline 0.25 & 0.5378 & 0.5383 & 0.09 \\
\hline 0.3 & 0.5315 & 0.5338 & 0.43 \\
\hline 0.37 & 0.5173 & 0.5234 & 1.18 \\
\hline 0.43 & 0.5014 & 0.5107 & 1.85 \\
\hline 0.46 & 0.5 & 0.5026 & 0.52 \\
\hline $0.47-1$ & 0.5 & 0.5 & 0 \\
\hline
\end{tabular}

Note: Profit Gap $=100 *$ (Profit with Cross-purchasing - Profit without Crosspurchasing)/ Profit without Cross-purchasing

\section{Table A-1: Profits Comparison between the Two Scenarios}

In Table A-1, we show the comparison of the monopolist's profits in the two scenarios. We show that for $0 \leq q_{a} \leq 0.2$ and $q_{a} \geq 0.47$, the monopolist's versioning strategies as well as optimal profits are the same. For $0.2<q_{a}<0.47$, cross-purchasing does increase the monopolist's profits as it effectively removes a constraint - the IC condition. However, our numerical example shows that the profit gap is less than $2 \%$. Moreover, as the monopolist already knows the consumer groups, during development versions are designed for specific groups. Therefore, information goods are designed and targeted for separate market segments such that cross-purchasing rarely occurs.

\section{A.5. Proof of Lemma 1}

According to our Assumption 4 about utility with hierarchical characteristics, the lower taste groups do not value characteristics designed for higher taste groups, thus consumers in the lower tastes group never cross-purchase the information goods customized for higher taste groups.

Now we consider the situation when the higher taste groups cross-purchase. Because there is no cross-purchasing from the lowest taste group, group 1 , the price $p_{1}$ of version $q_{1}$ is determined by the IR condition: $p_{1}=k_{1} \tilde{\theta}_{1} q_{1}$, where $\tilde{\theta}_{1}$ is the consumer indifferent between purchasing and not in group 1. From the utility structure in Assumption 4, all consumers 
with higher individual taste than $\tilde{\theta}_{1}$ get positive surplus from purchasing $q_{1}$. Thus, if a separate version $q_{1}$ is offered, then all the higher taste groups must be covered.

For group 2, if there is cross-purchasing, then for the indifferent consumer $\tilde{\theta}_{2}$ in group 2 , consumers are divided into two segments: consumers in $\left[\theta_{1}, \tilde{\theta}_{2}\right)$ purchase $q_{1}$ while consumers in $\left(\tilde{\theta}_{2}, \theta_{2}\right)$ purchase $q_{2} \cdot p_{2}$ of version $q_{2}$ is determined by the IC condition so that: $k_{2} \tilde{\theta}_{2} q_{2}-p_{2}=$ $k_{2} \tilde{\theta}_{2} q_{1}-p_{1}$.

For group 3, if there is cross-purchasing, then the consumer surplus from purchasing $q_{2}$ is $k_{3} \theta q_{2}-p_{2}$ and from purchasing $q_{1}$ is $k_{3} \theta q_{1}-p_{1}$. From the price relationship of $p_{1}$ and $p_{2}$ above, we have

$$
\left(k_{3} \theta q_{2}-p_{2}\right)-\left(k_{3} \theta q_{1}-p_{1}\right)=\left(k_{3} \theta-k_{2} \tilde{\theta}_{2}\right)\left(q_{2}-q_{1}\right)>0, \quad \theta \in\left[\theta_{2}, \theta_{3}\right) .
$$

Thus, if there is cross-purchasing, then consumers in group 3 only cross-purchase $q_{2}$. Following the same logic, if there is cross-purchasing from group $n$, then consumers in this group only cross-purchase the version $q_{n-1}$, a version designed for their adjacent lower group. Thus, $p_{n}$ of version $q_{n}$ is determined by the IC condition so that: $k_{n} \tilde{\theta}_{n} q_{n}-p_{n}=k_{n} \tilde{\theta}_{n} q_{n-1}-p_{n-1}$, where $\tilde{\theta}_{n}$ is the indifferent consumer in group $n$ that is indifferent between purchasing $q_{n}$ and $q_{n-1}$. The monopolist's profit maximization problem is:

$\max _{\tilde{\theta}_{1}, \cdots, \tilde{\theta}_{h}} \Pi\left(\tilde{\theta}_{1}, \cdots, \tilde{\theta}_{h}\right)=\max _{\tilde{\theta}_{1}, \cdots, \tilde{\theta}_{h}}\left\{\sum_{n=1}^{h-1} p_{n}\left[F\left(\tilde{\theta}_{n+1}\right)-F\left(\tilde{\theta}_{n}\right)\right]+p_{h}\left[1-F\left(\tilde{\theta}_{h}\right)\right]\right\}$ s.t. $\tilde{\theta}_{n} \in\left[\theta_{n-1}, \theta_{n}\right)$.

Substituting prices into the above, we have

$$
\Pi\left(\tilde{\theta}_{1}, \cdots, \tilde{\theta}_{h}\right)=k_{1} \tilde{\theta}_{1} q_{1}\left[1-F\left(\tilde{\theta}_{1}\right)\right]+\sum_{n=2}^{h} k_{n} \tilde{\theta}_{n}\left(q_{n}-q_{n-1}\right)\left[1-F\left(\tilde{\theta}_{n}\right)\right] \text { s.t. } \tilde{\theta}_{n} \in\left[\theta_{n-1}, \theta_{n}\right) .
$$

The first order conditions with respect to $\tilde{\theta}_{1}, \cdots, \tilde{\theta}_{h}$ give that $\tilde{\theta}_{n}=\frac{1-F\left(\tilde{\theta}_{n}\right)}{f\left(\tilde{\theta}_{n}\right)}$ such that $n \in$ $\{1, \cdots, h\}, \tilde{\theta}_{n} \in\left[\theta_{n-1}, \theta_{n}\right)$. According to Assumption 1 , there is unique solution for $\theta=$ $\frac{1-F(\theta)}{f(\theta)}$, which means the indifferent consumers in all groups converge. It indicates that except for the group that this unique solution belongs to (which we show in the proof A.5. Derivation of $\tilde{\theta}_{e}$ below) is partially covered with a customized version, all higher groups are covered by one version only while all lower groups are not served at all. Consequently, there is no cross-purchasing by any group. 
To conclude, we get that for a lower taste group to be provided with an information good customized for it, all higher taste groups must be covered and there is no cross-purchasing among different groups.

\section{A.6. Derivation of $\tilde{\theta}_{e}$}

With Lemma 1 we can restate the profit maximization in (3) as the optimal choice of a single indifferent consumer across the consumer groups:

$$
\begin{aligned}
& \max _{\tilde{\theta}_{i}} \Pi\left(\tilde{\theta}_{i}\right)= \\
& \max _{\tilde{\theta}_{i}}\left\{k_{i} \tilde{\theta}_{i} q_{i}\left[F\left(\theta_{i}\right)-F\left(\tilde{\theta}_{i}\right)\right]+\sum_{n=i+1}^{h}\left[k_{i} \tilde{\theta}_{i} q_{i}+\sum_{m=i+1}^{n} k_{m} \theta_{m-1}\left[q_{m}-q_{m-1}\right]\right]\left[F\left(\theta_{n}\right)-F\left(\theta_{n-1}\right)\right]\right\} ; \\
& \text { s.t. } i \in\{1, \cdots, h\}, \tilde{\theta}_{i} \in\left[\theta_{i-1}, \theta_{i}\right),[\mathrm{IR}],[\mathrm{IC}] .
\end{aligned}
$$

The profit maximization in (15) does not necessarily ensure that each higher taste group than $i$ is provided with a separate version. That is, multiple adjacent groups may share the same version such that, for example, a given group $m+1$ shares the same version as group $m$ and then $q_{m+1}=q_{m}$. Breaking the summation of the second part of (15) and combining all the $\tilde{\theta}_{i}$ and $\theta_{n}, n \in\{i, \ldots, h\}$, we restate the monopolist's profit maximization as

$$
\max _{\tilde{\theta}_{i}} \Pi\left(\tilde{\theta}_{i}\right)=\max _{\tilde{\theta}_{i}}\left\{k_{i} \tilde{\theta}_{i} q_{i}\left[1-F\left(\tilde{\theta}_{i}\right)\right]+\sum_{n=i+1}^{h} k_{n} \theta_{n-1}\left[q_{n}-q_{n-1}\right]\left[1-F\left(\theta_{n-1}\right)\right]\right\} .
$$

Using Assumption 1, we denote the unique solution for $\theta=\frac{1-F(\theta)}{f(\theta)}, \theta \in\left[\theta_{0}, \theta_{h}\right]$ by $\tilde{\theta}_{e}$, which is in group $e$. Consequently, $\theta[1-F(\theta)]$ increases with $\theta$ when $\theta<\tilde{\theta}_{e}$ and decreases when $\theta>\tilde{\theta}_{e}$. This can be seen as follows: define a function $\psi(\theta)=\theta[1-F(\theta)]$, then $\psi^{\prime}(\theta)=f(\theta)\left[\frac{1-F(\theta)}{f(\theta)}-\theta\right]$ and $\psi^{\prime}\left(\tilde{\theta}_{e}\right)=0$. Because $\frac{1-F(\theta)}{f(\theta)}$ is non-increasing in $\theta$, we get $\psi^{\prime}(\theta)>0$ when $\theta<\tilde{\theta}_{e}$ and $\psi^{\prime}(\theta)<0$ when $\theta>\tilde{\theta}_{e}$. From Lemma 1 and given that $\tilde{\theta}_{e}$ is unique, lower taste groups than $e$ are not served.

\section{A.7. Proof of Theorem 2}

The proof proceeds by first establishing that the condition is necessary and sufficient for more than one group to be served. Then we show that it is optimal to version. To simplify expressions in the proof we denoted $\tilde{\theta}_{i}$ as the indifferent consumer in the lowest taste group $i$ that is served. It is straightforward from our discussion after Lemma 1 that if $i=e$, then 
$\tilde{\theta}_{i}=\tilde{\theta}_{e}$ and if $i>e$, then $\tilde{\theta}_{i}=\theta_{i-1}$. $\left(\tilde{\theta}_{i}\right)$ is denoted as the monopolist's profits from serving group $i$ and covering all the higher taste groups.

Necessity: Suppose the condition in the premise cannot be satisfied. Using Lemma 1, the monopolist's profits from serving group $i$ and covering all the higher taste groups are

$$
\begin{aligned}
\Pi\left(\tilde{\theta}_{i}\right)= & k_{i} \tilde{\theta}_{i} q_{i}\left[1-F\left(\tilde{\theta}_{i}\right)\right]+\sum_{n=i+1}^{h} k_{n} \theta_{n-1}\left[q_{n}-q_{n-1}\right]\left[1-F\left(\theta_{n-1}\right)\right] \\
= & k_{i} \tilde{\theta}_{i} q_{i}\left[1-F\left(\tilde{\theta}_{i}\right)\right]+\sum_{n=i+1}^{h-1} k_{n} \theta_{n-1}\left[q_{n}-q_{n-1}\right]\left[1-F\left(\theta_{n-1}\right)\right] \\
& +k_{h} \theta_{h-1}\left[q_{h}-q_{h-1}\right]\left[1-F\left(\theta_{h-1}\right)\right] \\
< & k_{h} \theta_{h-1} q_{i}\left[1-F\left(\theta_{h-1}\right)\right]+\sum_{n=i+1}^{h-1} k_{h} \theta_{h-1}\left[q_{n}-q_{n-1}\right]\left[1-F\left(\theta_{h-1}\right)\right] \\
& +k_{h} \theta_{h-1}\left[q_{h}-q_{h-1}\right]\left[1-F\left(\theta_{h-1}\right)\right] \\
< & k_{h} \theta_{h-1} q_{h-1}\left[1-F\left(\theta_{h-1}\right)\right]+k_{h} \theta_{h-1}\left[q_{h}-q_{h-1}\right]\left[1-F\left(\theta_{h-1}\right)\right] \\
= & \Pi\left(\theta_{h-1}\right),
\end{aligned}
$$

noting that $k_{h} \theta_{h-1}\left[1-F\left(\theta_{h-1}\right)\right]$ can be taken outside the summation in the first right hand side expression. This means that profits from serving more groups than just the highest taste group are less than profits from serving, and covering, the highest taste group. Thus, it is optimal for the monopolist to serve only one group.

Sufficiency: Suppose the monopolist only provides two versions, one for group $i<h$ and the other for group $h$. Consumers in groups $i, \ldots, h-1$ choose $q_{i}$ and consumers in group $h$ choose $q_{h}$. The monopolist's profits are

$$
\Pi\left(\tilde{\theta}_{i}\right)=k_{i} \tilde{\theta}_{i} q_{i}\left[1-F\left(\tilde{\theta}_{i}\right)\right]+k_{h} \theta_{h-1}\left[q_{h}-q_{i}\right]\left[1-F\left(\theta_{h-1}\right)\right]>k_{h} \theta_{h-1} q_{h}\left[1-F\left(\theta_{h-1}\right)\right]=\Pi\left(\theta_{h-1}\right) .
$$

Thus, the monopolist increases profits by serving at least two groups with $q_{i}$ and $q_{h}$.

Versioning: Suppose $\tilde{\theta}_{i} \in\left[\theta_{h-2}, \theta_{h-1}\right)$ so that two groups are served. Then the monopolist can offer either $q_{h}, q_{h-1}$, or both. From Assumption 4 and the IR condition, if either $q_{h}$ or $q_{h-1}$ are offered, then the price is $k_{h-1} \tilde{\theta}_{i} q_{h-1} \geq p_{h}=p_{h-1}$. If the monopolist offers $q_{h}$ and $q_{h-1}$, then from the IR condition prices are

$$
k_{h} \theta_{h-1} q_{h} \geq p_{h} \text { and } k_{h-1} \tilde{\theta}_{i} q_{h-1} \geq p_{h-1} .
$$


From the IC condition

$$
k_{h} \theta_{h-1} q_{h}-p_{h} \geq k_{h} \theta_{h-1} q_{h-1}-p_{h-1}>k_{h-1} \tilde{\theta}_{i} q_{h-1}-p_{h-1} \geq 0 .
$$

As $q_{h}>q_{h-1}$, then $p_{h}>p_{h-1}$, and it is more profitable to version.

\section{A.8. Proof of Proposition 2}

We examine three cases: 1) $g$ is the lowest taste group served, which means $g=i$; 2) $g$ is the highest taste group, which means $g=h$, and 3) $g$ is a middle taste group, which means $i<g<h$. All the notation follows those in the proof of Theorem 2 .

Case 1: $g$ is the lowest taste group that is served

Necessity: Suppose the condition in the premise does not hold. Assume there exists a $\tilde{\theta}_{m} \in\left[\theta_{g-1}, \theta_{h}\right]$ belonging to group $m>g$ so that $k_{m} \theta[1-F(\theta)]$ is maximized at $\tilde{\theta}_{m}$. Then

$$
\begin{aligned}
& \Pi\left(\tilde{\theta}_{m}\right)= \\
& \quad k_{m} \tilde{\theta}_{m} q_{m}\left[1-F\left(\tilde{\theta}_{m}\right)\right]+\sum_{n=m+1}^{h} k_{n} \theta_{n-1}\left[q_{n}-q_{n-1}\right]\left[1-F\left(\theta_{n-1}\right)\right] \\
& =k_{m} \tilde{\theta}_{m}\left[1-F\left(\tilde{\theta}_{m}\right)\right]\left\{q_{g}+\sum_{n=g+1}^{m}\left[q_{n}-q_{n-1}\right]\right\}+\sum_{n=m+1}^{h} k_{n} \theta_{n-1}\left[q_{n}-q_{n-1}\right]\left[1-F\left(\theta_{n-1}\right)\right] \\
& >k_{g} \tilde{\theta}_{g} q_{g}\left[1-F\left(\tilde{\theta}_{g}\right)\right]+\sum_{n=g+1}^{m} k_{n} \theta_{n-1}\left[q_{n}-q_{n-1}\right]\left[1-F\left(\theta_{n-1}\right)\right]+\sum_{n=m+1}^{h} k_{n} \theta_{n-1}\left[q_{n}-q_{n-1}\right]\left[1-F\left(\theta_{n-1}\right)\right] \\
& =\Pi\left(\tilde{\theta}_{g}\right) .
\end{aligned}
$$

This shows that profits increase by not serving groups $g, \ldots, m-1$, which contradicts that group $g$ is served.

Sufficiency: Because $k_{g} \theta[1-F(\theta)]$ is maximized at $\tilde{\theta}_{g}$ for $\theta \in\left[\theta_{g-1}, \theta_{h}\right]$, we have

$$
\begin{aligned}
& \Pi\left(\tilde{\theta}_{g}\right)= \\
& \quad k_{g} \tilde{\theta}_{g} q_{g}\left[1-F\left(\tilde{\theta}_{g}\right)\right]+\sum_{n=g+1}^{h} k_{n} \theta_{n-1}\left[q_{n}-q_{n-1}\right]\left[1-F\left(\theta_{n-1}\right)\right] \\
& =k_{g} \tilde{\theta}_{g} q_{g}\left[1-F\left(\tilde{\theta}_{g}\right)\right]+k_{g+1} \theta_{g}\left[q_{g+1}-q_{g}\right]\left[1-F\left(\theta_{g}\right)\right]+\sum_{n=g+2}^{h} k_{n} \theta_{n-1}\left[q_{n}-q_{n-1}\right]\left[1-F\left(\theta_{n-1}\right)\right] \\
& >k_{g+1} \theta_{g} q_{g+1}\left[1-F\left(\theta_{g}\right)\right]+\sum_{n=g+2}^{h} k_{n} \theta_{n-1}\left[q_{n}-q_{n-1}\right]\left[1-F\left(\theta_{n-1}\right)\right] \\
& =\Pi\left(\tilde{\theta}_{g+1}\right) .
\end{aligned}
$$


Thus, profits decrease when group $g$ is not provided with a separate version.

Case 2: $g$ is the highest taste group

In this case it is always true that $k_{g} \theta[1-F(\theta)]$ is maximized at $\tilde{\theta}_{g}$ for $\theta \in\left[\theta_{g-1}, \theta_{h}\right]$. From the proof of Proposition 2, the highest group $h$ is always served with the highest version $q_{h}$ which is customized for it.

Case 3: $g$ is a middle taste group

Necessity: Suppose the condition in the premise does not hold. As in Case 1, assume there exists a $\tilde{\theta}_{m} \in\left[\theta_{g-1}, \theta_{h}\right]$ belonging to group $m>g$ so that $k_{m} \theta[1-F(\theta)]$ is maximized at $\tilde{\theta}_{m}$. Then we have

$$
\begin{aligned}
\Pi\left(\tilde{\theta}_{i}\right)= & k_{i} \tilde{\theta}_{i} q_{i}\left[1-F\left(\tilde{\theta}_{i}\right)\right]+\sum_{n=i+1}^{h} k_{n} \theta_{n-1}\left[q_{n}-q_{n-1}\right]\left[1-F\left(\theta_{n-1}\right)\right] \\
= & k_{i} \tilde{\theta}_{i} q_{i}\left[1-F\left(\tilde{\theta}_{i}\right)\right]+\sum_{n=i+1}^{g-1} k_{n} \theta_{n-1}\left[q_{n}-q_{n-1}\right]\left[1-F\left(\theta_{n-1}\right)\right] \\
& +\sum_{n=g}^{m} k_{n} \theta_{n-1}\left[q_{n}-q_{n-1}\right]\left[1-F\left(\theta_{n-1}\right)\right]+\sum_{n=m+1}^{h} k_{n} \theta_{n-1}\left[q_{n}-q_{n-1}\right]\left[1-F\left(\theta_{n-1}\right)\right] \\
< & k_{i} \tilde{\theta}_{i} q_{i}\left[1-F\left(\tilde{\theta}_{i}\right)\right]+\sum_{n=i+1}^{g-1} k_{n} \theta_{n-1}\left[q_{n}-q_{n-1}\right]\left[1-F\left(\theta_{n-1}\right)\right] \\
& +\sum_{n=g}^{m} k_{m} \theta_{m-1}\left[q_{n}-q_{n-1}\right]\left[1-F\left(\theta_{m-1}\right)\right]+\sum_{n=i+1}^{g-1} k_{n} \theta_{n-1}\left[q_{n}-q_{n-1}\right]\left[1-F\left(\theta_{n-1}\right)\right] \\
= & k_{i} \tilde{\theta}_{i} q_{i}\left[1-F\left(\tilde{\theta}_{i}\right)\right]+\sum_{n=i+1}^{g-1} k_{n} \theta_{n-1}\left[q_{n}-q_{n-1}\right]\left[1-F\left(\theta_{n-1}\right)\right] \\
& +k_{m} \theta_{m-1}\left[q_{m}-q_{g-1}\right]\left[1-F\left(\theta_{m-1}\right)\right]+\sum_{n=m+1}^{h} k_{n} \theta_{n-1}\left[q_{n}-q_{n-1}\right]\left[1-F\left(\theta_{n-1}\right)\right] .
\end{aligned}
$$

This shows that profits increase when $q_{g-1}=\ldots=q_{m-1}$, which means consumers in groups $g, \ldots, m-1$ purchase the same version as group $g-1$. That is, groups $g, \ldots, m-1$ are pooled together. Thus, there is no separate version customized for group $g$. 
Sufficiency: Because $k_{g} \theta[1-F(\theta)]$ is maximized at $\tilde{\theta}_{g}$ for $\theta \in\left[\theta_{g-1}, \theta_{h}\right]$, we have

$$
\begin{aligned}
\Pi\left(\tilde{\theta}_{i}\right)= & k_{i} \tilde{\theta}_{i} q_{i}\left[1-F\left(\tilde{\theta}_{i}\right)\right]+\sum_{n=i+1}^{h} k_{n} \theta_{n-1}\left[q_{n}-q_{n-1}\right]\left[1-F\left(\theta_{n-1}\right)\right] \\
= & k_{i} \tilde{\theta}_{i} q_{i}\left[1-F\left(\tilde{\theta}_{i}\right)\right]+\sum_{n=i+1}^{g-1} k_{n} \theta_{n-1}\left[q_{n}-q_{n-1}\right]\left[1-F\left(\theta_{n-1}\right)\right] \\
& +k_{g} \theta_{g-1}\left[q_{g}-q_{g-1}\right]\left[1-F\left(\theta_{g-1}\right)\right]+k_{g+1} \theta_{g}\left[q_{g+1}-q_{g}\right]\left[1-F\left(\theta_{g}\right)\right] \\
& +\sum_{n=g+2}^{h} k_{n} \theta_{n-1}\left[q_{n}-q_{n-1}\right]\left[1-F\left(\theta_{n-1}\right)\right] \\
> & k_{i} \tilde{\theta}_{i} q_{i}\left[1-F\left(\tilde{\theta}_{i}\right)\right]+\sum_{n=i+1}^{g-1} k_{n} \theta_{n-1}\left[q_{n}-q_{n-1}\right]\left[1-F\left(\theta_{n-1}\right)\right] \\
& +k_{g} \theta_{g-1}\left[q_{g}-q_{g-1}\right]\left[1-F\left(\theta_{g-1}\right)\right]+k_{g} \theta_{g-1}\left[q_{g+1}-q_{g}\right]\left[1-F\left(\theta_{g-1}\right)\right] \\
& +\sum_{n=g+2}^{h} k_{n} \theta_{n-1}\left[q_{n}-q_{n-1}\right]\left[1-F\left(\theta_{n-1}\right)\right] \\
= & k_{i} \tilde{\theta}_{i} q_{i}\left[1-F\left(\tilde{\theta}_{i}\right)\right]+\sum_{n=i+1}^{g-1} k_{n} \theta_{n-1}\left[q_{n}-q_{n-1}\right]\left[1-F\left(\theta_{n-1}\right)\right] \\
& +k_{g} \theta_{g-1}\left[q_{g+1}-q_{g-1}\right]\left[1-F\left(\theta_{g-1}\right)\right]+\sum_{n=g+2}^{h} k_{n} \theta_{n-1}\left[q_{n}-q_{n-1}\right]\left[1-F\left(\theta_{n-1}\right)\right] .
\end{aligned}
$$

Hence, profits decrease when group $g$ is offered the same version as group $g-1$. Thus the monopolist must set $q_{g}>q_{g-1}$, which means that a separate version is customized for group $g$.

Combining the above three cases completes the proof. 